\title{
INVESTIGATION OF FLY ASH AND ACTIVATED CARBON OBTAINED FROM PULVERIZED COAL BOILERS
}

\author{
FINAL REPORT
}

September 1, 2003 to August 31, 2006

Edward K. Levy, Christopher Kiely and Zheng Yao

November, 2006

DE - FG26-03NT41796

Energy Research Center

Lehigh University

117 ATLSS Drive

Bethlehem, PA 18015 


\section{DISCLAIMER}

"This report was prepared as an account of work sponsored by an agency of the United States Government. Neither the United States Government nor any agency thereof, nor any of their employees, makes any warranty, express or implied, or assumes any legal liability or responsibility for the accuracy, completeness, or usefulness of any information, apparatus, product, or process disclosed, or represents that its use would not infringe privately owned rights. Reference herein to any specific commercial product, process, or service by trade name, trademark, manufacturer, or otherwise does not necessarily constitute or imply its endorsement, recommendation, or favoring by the United States Government or any agency thereof. The views and opinions of authors expressed herein do not necessarily state or reflect those of the United States Government or any agency thereof."

\section{ACKNOWLEDGEMENTS}

The authors of this report are grateful to the following individuals for their assistance in carrying out the various tasks:

- Dr. Andrew Burrows, Electron Microscopy Specialist in Materials Science

- Brian Celeste, Graduate Student in Mechanical Engineering

- Dr. Alfred Miller, Research Scientist in Chemistry 


\section{ABSTRACT}

One of the techniques for $\mathrm{Hg}$ capture in coal-fired boilers involves injection of activated carbon $(\mathrm{AC})$ into the boiler downstream of the air preheater. $\mathrm{Hg}$ is adsorbed onto the AC particles and fly ash, which are then both removed in an electrostatic precipitator or baghouse.

This project addressed the issues of $\mathrm{Hg}$ on activated carbon and on fly ash from a materials re-use point of view. It also addressed the possible connection between SCR reactors, fly ash properties and $\mathrm{Hg}$ capture. The project has determined the feasibility of separating $A C$ from fly ash in a fluidized bed and of regenerating the separated $A C$ by heating the $A C$ to elevated temperatures in a fluidized bed. The temperatures needed to drive off the $\mathrm{Hg}$ from the ash in a fluidized bed have also been determined. Finally, samples of fly ash from power plants with SCR reactors for $\mathrm{NO}_{x}$ control have been analyzed in an effort to determine the effects of SCR on the ash. 


\section{TABLE OF CONTENTS}

Page

INTRODUCTION

Background 1

Objectives 2

EXECUTIVE SUMMARY 3

Background 3

Results and Recommendations 3

Separation of Activated Carbon and Fly Ash in a Fluidized Bed 3

Relation Between Mercury Concentration and Carbon Content 3

Removal of Hg From Activated Carbon and Fly Ash 4

Morphologies of Fly Ash and Activated Carbon 4

Detection of $\mathrm{Hg}$ on Individual Carbon Particles 4

Effect of SCR on Fly Ash Surface Chemistry 5

$\begin{array}{lr}\text { EXPERIMENTAL } & 6\end{array}$

Task 1: Separation of Activated Carbon and Fly Ash in a Fluidized Bed 6

Task 2: Removal of Hg from Activated Carbon and Fly Ash 9

Task 3: Microstructural and Chemical Analysis of Fly Ash and Activated 10 Carbon

Task 4: Effect of SCR on Ash Properties 12

$\begin{array}{ll}\text { RESULTS AND DISCUSSION } & 13\end{array}$

Separation of Activated Carbon and Fly Ash in a Fluidized Bed 13

Removal of Hg from Activated Carbon and Fly Ash 19

Morphologies of Fly-Ash/Activated Carbon Mixtures 23

General Characteristics 23

Additional Studies of Activated Carbon and Unburned Carbon 29 in Fly Ash

Fly Ash/AC Mixture Obtained by Segregation 30

Pure Activated Carbon $\quad 30$ 


\section{TABLE OF CONTENTS (continued)}

Page

Fly Ash With High Unburned Carbon 32

Detection of $\mathrm{Hg}$ on Individual Carbon Particles 35

Microstructural Characterization of Fly Ash Passing Through SCR 36 Catalysts

SUMMARY AND CONCLUSIONS $\quad 40$

Separation of Activated Carbon and Fly Ash in a Fluidized Bed $\quad 40$

Relation Between Mercury Concentration and Carbon Content 40

Removal of Hg from Activated Carbon and Fly Ash 40

Morphologies of Fly Ash and Activated Carbon $\quad 41$

Detection of $\mathrm{Hg}$ on Individual Carbon Particles 42

Effect of SCR on Fly Ash Surface Chemistry 42

$\begin{array}{lr}\text { REFERENCES } & 42\end{array}$ 


\section{LIST OF FIGURES}

$\underline{\text { Figure }}$

Page

$1 \quad$ Laboratory Batch Fluidized Bed.

2 Variation of Minimum Bubbling Velocity with Sound Pressure Level.

7

3 Sketch Showing Layering Technique for Analysis of Carbon

8 Stratification in Fluidized Bed.

4 Vertical Stratification of Carbon and Hg. $V_{\text {air }}=0.6 \mathrm{~cm} / \mathrm{s}$.

$5 \quad$ Vertical Stratification of Carbon. $V_{\text {air }}=0.7 \mathrm{~cm} / \mathrm{s}$.

6 Vertical Stratification of $\mathrm{Hg}$ and Carbon. $V_{\text {air }}=0.7 \mathrm{~cm} / \mathrm{s}$.

$7 \quad$ Vertical Stratification of $\mathrm{Hg}$ and Carbon. $\mathrm{V}_{\text {air }}=0.8 \mathrm{~cm} / \mathrm{s}$.

8 Vertical Stratification of Carbon. $V_{\text {air }}=0.9 \mathrm{~cm} / \mathrm{s}$.

9 Vertical Stratification of Carbon. $V_{\text {air }}=1.1 \mathrm{~cm} / \mathrm{s}$.

Magnitude of Carbon Stratification Versus Superficial Air Velocity.

11 Minimum Fluidization Velocity From Bed Pressure Drop Test.

Hg Content Versus Carbon Content.

13 Bed Temperature Versus Time (High Carbon).

Hg Content Versus Bed Temperature (High Carbon).

Bed Temperature Versus Time (Medium Carbon).

Hg Content Versus Bed Temperature (Medium Carbon).

17 Bed Temperature Versus Time (Low Carbon). Microstructures That Can Co-Exist. 


\section{LIST OF FIGURES (continued)}

$\underline{\text { Figure }}$

Page

21 SEM Micrograph (a) and EDS Spectrum (b) From a Typical Particle of Unburnt Carbon.

SEM Micrograph (a) and EDS Spectrum (b) From a Typical Spherical Morphology Alumino-Silicate Particle.

23 SEM Micrographs From Large Carbon Particles Having a Hollow

26 Shell Morphology.

24 SEM Micrograph (a) and Corresponding EDS Elemental Map (b) From a Typical Hollow Morphology Carbon Particle.

25 TEM Micrograph of a Typical Agglomerate of Activated Carbon Particles

26 TEM Micrograph of an Alumino-Silicate Sphere Decorated with Activated Carbon Particles

27 An SEM Micrograph Showing the Typical Morphology of a 'Pure' Activated Carbon Sample.

EDS Spectrum Obtained From the Entire Area Imaged in Figure 27. 28

29 Bright Field TEM Micrograph Showing an Irregular Carbon Particle in the Pure AC Sample Decorated with Smaller Carbon Particles.

$30 \quad$ Higher Resolution Electron Micrograph of the Smaller Decoration Particles in Figure 29, Showing Them to be Amorphous Carbon.

31 Top Layer of FA-1 Fly Ash Segregation.

32 Bottom Layer of FA-1 Fly Ash Segregation.

33 Optical Microscopy Image of Pure Activated Carbon Particles. Optical Microscopy Image of Typical Pure Activated Carbon Particle. 33

35 SEM Image of Fly Ash With High Unburned Carbon. 


\section{LIST OF FIGURES (continued)}

Figure

$\underline{\text { Page }}$

38 Optical Microscopy of Typical Large Unburned Carbon Particles.

35

39 Bright Field Low Magnification Micrograph of the 'After' SCR

37 Samples

$40 \quad$ Bright Field Micrograph of a Typical Spherical Fly Ash Sample

38 Showing Surface Decoration with Carbon.

$41 \quad$ High Resolution Bright Field Micrograph of an Agglomerate of Amorphous Carbon Particles.

42 Widescan XPS Survey Spectra of the 'Before' and 'After' SCR

39 Materials.

43 Higher Resolution XPS Spectra From the 'Before' and 'After'

39 SCR Materials. 


\section{LIST OF TABLES}

$\underline{\text { Table }}$

Page

1 Fly Ash and Activated Carbon Samples Examined

30 


\section{INTRODUCTION}

\section{Background}

One of the techniques for mercury $(\mathrm{Hg})$ capture in coal-fired boilers involves injection of activated carbon $(A C)$ into the boiler downstream of the air preheater. $\mathrm{Hg}$ is adsorbed onto the $\mathrm{AC}$ particles and onto the fly ash, which are then both removed in an electrostatic precipitator or baghouse. While field trials with AC injection have demonstrated the ability to remove significant fractions of the $\mathrm{Hg}$ at some units, there are also problems in using $\mathrm{AC}$ for $\mathrm{Hg}$ capture. Activated carbon is relatively expensive, leading to high projected costs for $\mathrm{Hg}$ capture. The AC can increase opacity at units with electrostatic precipitators, due to increased particulate loading and the low resistivity of $A C$ particles. The feed rates of $A C$ required to control $\mathrm{Hg}$ can also result in significant increases in the carbon content of the ash. However, fly ash used in concrete must have carbon contents of 4 percent or less in order that the concrete have acceptable mechanical properties. This has raised concerns that widespread use of AC for $\mathrm{Hg}$ capture will eliminate concrete as a viable market for re-use of ash, thereby greatly reducing the percentage of coal ash which can be re-used.

Data reported in the literature on field tests at boilers equipped with Selective Catalytic Reduction (SCR) reactors show that SCR reactors promote oxidation of elemental $\mathrm{Hg}$, which then results in increased capture of flue gas $\mathrm{Hg}$ by fly ash particles. However, the actual mechanisms for the enhanced oxidation in the SCR reactor have not yet been adequately explained.

This project addressed the issues of $\mathrm{Hg}$ on activated carbon and on fly ash from a materials re-use point of view. It also addressed the possible connection between SCR reactors, fly ash characteristics and $\mathrm{Hg}$ capture. The project determined the feasibility of separating $A C$ from fly ash in a fluidized bed and of regenerating the separated $A C$ by heating the $A C$ to elevated temperatures in a fluidized bed. The project also determined the temperatures needed to drive off the $\mathrm{Hg}$ from the ash in a fluidized bed. Finally, samples of fly ash from power plants with SCR reactors for $\mathrm{NO}_{x}$ control were analyzed in an effort to determine the effects of SCR on the ash. 


\section{Objectives}

The specific objectives of this project were as follows:

- Determine the potential for separation of $\mathrm{AC}$ from fly ash in a bubbling fluidized bed

- Determine the temperatures needed to remove $\mathrm{Hg}$ from spent $\mathrm{AC}$ in a bubbling fluidized bed, thereby creating the possibility of recycling regenerated $A C$ back to the boiler

- Determine the temperatures needed to remove $\mathrm{Hg}$ from fly ash in a bubbling fluidized bed

- Determine which components of fly ash are important for $\mathrm{Hg}$ capture

- Determine if SCR reactors affect fly ash chemistry in relation to $\mathrm{Hg}$ capture 


\section{EXECUTIVE SUMMARY}

\section{Background}

One of the techniques for mercury $(\mathrm{Hg})$ capture in coal-fired boilers involves injection of activated carbon (AC) into the boiler downstream of the air preheater. $\mathrm{Hg}$ is adsorbed onto the AC particles and fly ash, which are then removed in an electrostatic precipitator or baghouse.

This project addressed the issues of $\mathrm{Hg}$ on activated carbon and fly ash from a materials re-use point of view. It also addressed the possible connection between Selective Catalytic Reduction (SCR) reactors, fly ash properties and Hg capture. The project determined the feasibility of separating $A C$ from fly ash in a bubbling fluidized bed and of regenerating the separated $A C$ by heating the $A C$ to elevated temperatures in a fluidized bed. The temperatures needed to drive the $\mathrm{Hg}$ from the fly ash in a fluidized bed were also determined. Finally, samples of fly ash from power plants with SCR for $\mathrm{NO}_{x}$ control were analyzed to determine the effects of SCR on the ash surface chemistry.

\section{Results and Recommendations}

Separation of Activated Carbon and Fly Ash in a Fluidized Bed. Experiments were performed with a mixture of activated carbon and fly ash to determine to what extent the unburned carbon in the fly ash and the activated carbon can be separated from the inert portion of the fly ash in a bubbling fluidized bed. The data show that carbon segregation is very sensitive to superficial gas velocity, with the strongest segregation occurring at superficial velocities of 0.7 to $0.8 \mathrm{~cm} / \mathrm{s}$. At these conditions, the carbon content at the top of the bed was approximately 27 percent and it was less than 17 percent in the bottom layer. Very little or no carbon segregation occurred at fluidization velocities much lower than 0.7 to $0.8 \mathrm{~cm} / \mathrm{s}$ or higher than $1.1 \mathrm{~cm} / \mathrm{s}$.

While these experiments show it is possible to achieve carbon separation in a bubbling fluidized bed, the differences in particle density between the carbon particles and the inert fly ash particles appear not to be large enough to make this separation approach practical for commercial applications. There are other particle separation techniques based on triboelectric and electrostatic principles, and these might be better suited for this application. It is recommended that feasibility tests be performed on $\mathrm{AC} /$ fly ash mixtures using the triboelectric and electrostatic approaches.

Relation Between Mercury Concentration and Carbon Content. Multistage separation experiments were performed on the AC/fly ash mixture to expand the range of carbon contents between the top and bottom layers of the fluidized bed. Analyses of carbon and bulk mercury contents of the samples obtained from these tests show a strong linear relationship between $\mathrm{Hg}$ and carbon content, with the bulk $\mathrm{Hg}$ content approaching zero as the carbon content of the material goes towards zero. 
Removal of $\mathrm{Hg}$ from Activated Carbon and Fly Ash. Elevated temperature fluidized bed experiments were performed on the low carbon content mixture from the bottom layers of the fluidized bed, on the high carbon content mixture from the top layers of the fluidized bed and on AC/ash mixture with average carbon content. All behaved qualitatively the same way, with a constant $\mathrm{Hg}$ content until a critical temperature was reached and then with rapidly decreasing $\mathrm{Hg}$ content as the temperature was increased to higher levels. The critical temperature was found to be a linear function of carbon content, increasing from $330^{\circ} \mathrm{C}$ at 17 percent carbon to $370^{\circ} \mathrm{C}$ at 33 percent carbon. The temperature at which all of the $\mathrm{Hg}$ was removed is in the 450 to $500^{\circ} \mathrm{C}$ range.

These results confirm that it is possible to remove $\mathrm{Hg}$ from $\mathrm{AC}$ and fly ash particles by heating the material in air, but that particle temperatures as high as $500^{\circ} \mathrm{C}$ would be needed to remove all the $\mathrm{Hg}$. If it were desired to use this approach to regenerate used $\mathrm{AC}$, experiments would first be needed to determine if the $\mathrm{Hg}$ adsorption properties of the $\mathrm{AC}$ are changed by having been heated to these temperatures.

The test results also show that the $\mathrm{Hg}$ on fly ash and $\mathrm{AC}$ will not be released to the atmosphere through heating of the material, provided the temperatures do not exceed $300^{\circ} \mathrm{C}$.

Morphologies of Fly Ash and Activated Carbon. Scanning Electron (SEM) and Transmission Electron (TEM) Microscopes were used to study the physical and chemical characteristics of the $\mathrm{AC} /$ ash mixture used in the fluidized bed separation experiments. Five distinct morphologies were identified: large $(30-100 \mu \mathrm{m})$ irregularlyshaped carbon particles, 0.1 to $20 \mu \mathrm{m}$ spherical alumino-silicate particles, 50-100 $\mu \mathrm{m}$ hollow carbon particles with porous walls, fine 50-200 nm amorphous carbon particles, and large 20-50 $\mu \mathrm{m}$ angular activated carbon particles.

Four additional ash and activated carbon samples were then evaluated by Light Optical and Scanning Electron Microscopy. SEM studies of the fly ash/AC mixture obtained from the fluidized bed segregation experiments showed marked differences between the materials from the top and bottom layers of the fluidized bed. The top layer was dominated by large, irregularly shaped particles while the bottom layer had more spherical high-mineral content particles. This finding is consistent with the physical mechanism of segregation which results in denser, smaller particles moving downward towards the distributor and lighter, larger particles floating at the top of the bed.

Light Optical Microscopy images of large (50 to 100 microns) activated carbon particles showed them to be irregular in shape and filled with voids. Light Optical Microscopy studies of a fly ash, with a high naturally-occurring carbon content, showed the carbon in fly ash (usually referred to as unburned carbon) has an internal structure which is similar in appearance to that of pure activated carbon.

Detection of $\mathrm{Hg}$ on Individual Carbon Particles. Measurements were performed with both Transmission Electron Microscopy (TEM) and X-Ray Photoelectron Spectroscopy (XPS) in an attempt to detect $\mathrm{Hg}$ on individual carbon particles. The results showed the $\mathrm{Hg}$ concentrations were too small to be detected by either measurement method. 
Effect of SCR on Fly Ash Surface Chemistry. Samples of fly ash were obtained from a boiler with a Selective Catalytic Reduction (SCR) reactor for $\mathrm{NO}_{x}$ control. These samples, which were obtained from upstream and downstream of the SCR, were analyzed by X-ray Photoelectron Spectroscopy (XPS) to determine the effects of the SCR on the surface chemistry of the fly ash. The most significant differences were as follows:

- The 'after' SCR material had a significant surface $\mathrm{Cl}$ content, while the 'before' SCR material was essentially devoid of $\mathrm{Cl}$.

- The surface S signal in the 'after' SCR sample was about half of that observed in the 'before' SCR sample.

- The surface Fe content shows the opposite trend to the $S$ signal. It was about 50 percent larger in the 'after' SCR sample than in the 'before' SCR sample. 


\section{EXPERIMENTAL}

This project was, predominately, an experimental study, involving experiments in fluidized beds and laboratory analyses of activated carbon and fly ash by electron microscopy methods and other analytical techniques.

\section{Task 1: Separation of Activated Carbon and Fly Ash in a Fluidized Bed}

Because of the strong solid phase mixing and gas-solids interactions which occur in a bubbling fluidized bed operated at gas velocities well above minimum fluidization, fluidized beds are in widespread use in industry for applications such as heat exchangers, combustors, gasifiers, chemical reactors, and solids dryers. However, at superficial gas velocities just slightly above minimum bubbling, the solids do not mix well, and as a result, particle segregation occurs in the vertical direction, with the more dense particles settling downward to wards the distributor and the lowest density particles moving towards the free surface of the bed (Ref. 1 and 2).

The activated carbon used in $\mathrm{Hg}$ capture field trials sponsored by EPRI and DOE has approximately the same mean particle size as fly ash (15 to $20 \mu \mathrm{m}$ mass mean diameter), but it has a lower particle density than fly ash due to the higher porosity of activated carbon (Ref. 3). It was expected this difference in particle density would make it possible to separate the bulk of the spent activated carbon from the fly ash in a fluidized bed, and the first group of experiments determined the bed operating conditions needed to accomplish this and the resulting degree of separation.

Previous research on the behavior of fly ash in bubbling fluidized beds showed that, under normal circumstances, fly ash can be difficult to fluidize. The very small particle size leads to significant attractive (Van der Waal) forces between particles which can make the ash cohesive. Fly ash falls into the category of Geldart type C powders, which exhibit gas channeling and spouting, instead of bubbling (Ref. 4). However, the research has also shown that cohesive powders can be made to bubble in a gas fluidized bed with the assistance of high intensity sound (Ref. 5 and 6). Figure 1 
shows a gas fluidized bed with a loudspeaker positioned above the free surface of the bed. The high intensity sound waves agitate the bed material, disrupt the inter-particle forces, and make it possible to obtain stable bubbling. Figure 2 shows the effect of sound pressure level (SPL) in the bed on minimum bubbling velocity for three cohesive powders, including fly ash (Ref. 6). The background SPL in the laboratory was $\sim 85 \mathrm{~dB}$. The data show the powders could not be made to fluidize unless the SPL exceeded 120 to $133 \mathrm{~dB}$. At higher values of SPL, the minimum bubbling velocity decreased with increasing SPL.
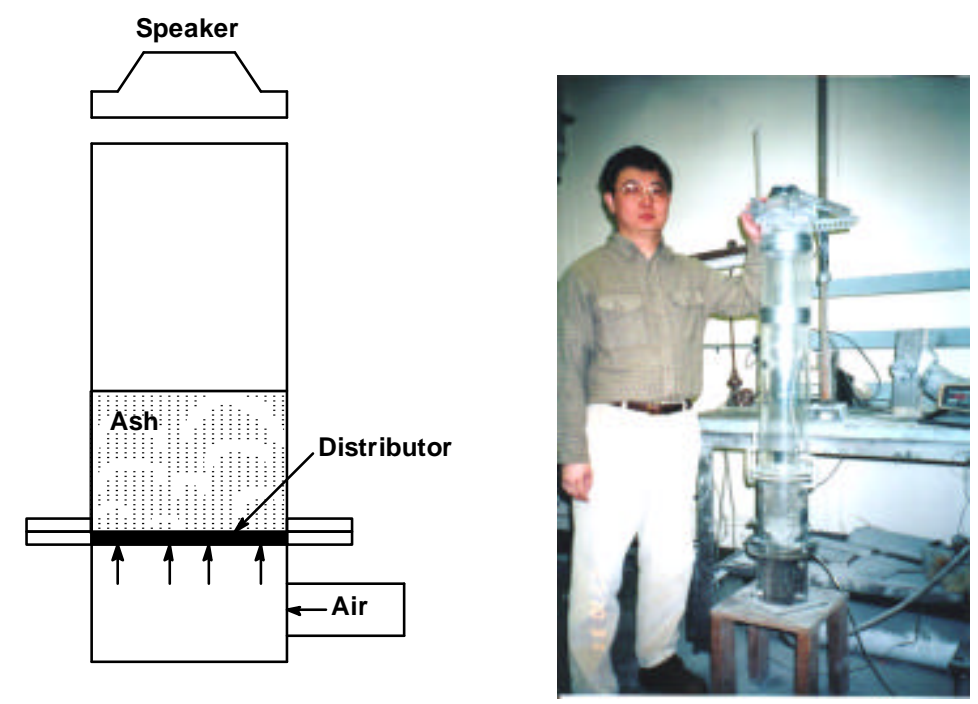

Figure 1: Laboratory Batch Fluidized Bed.

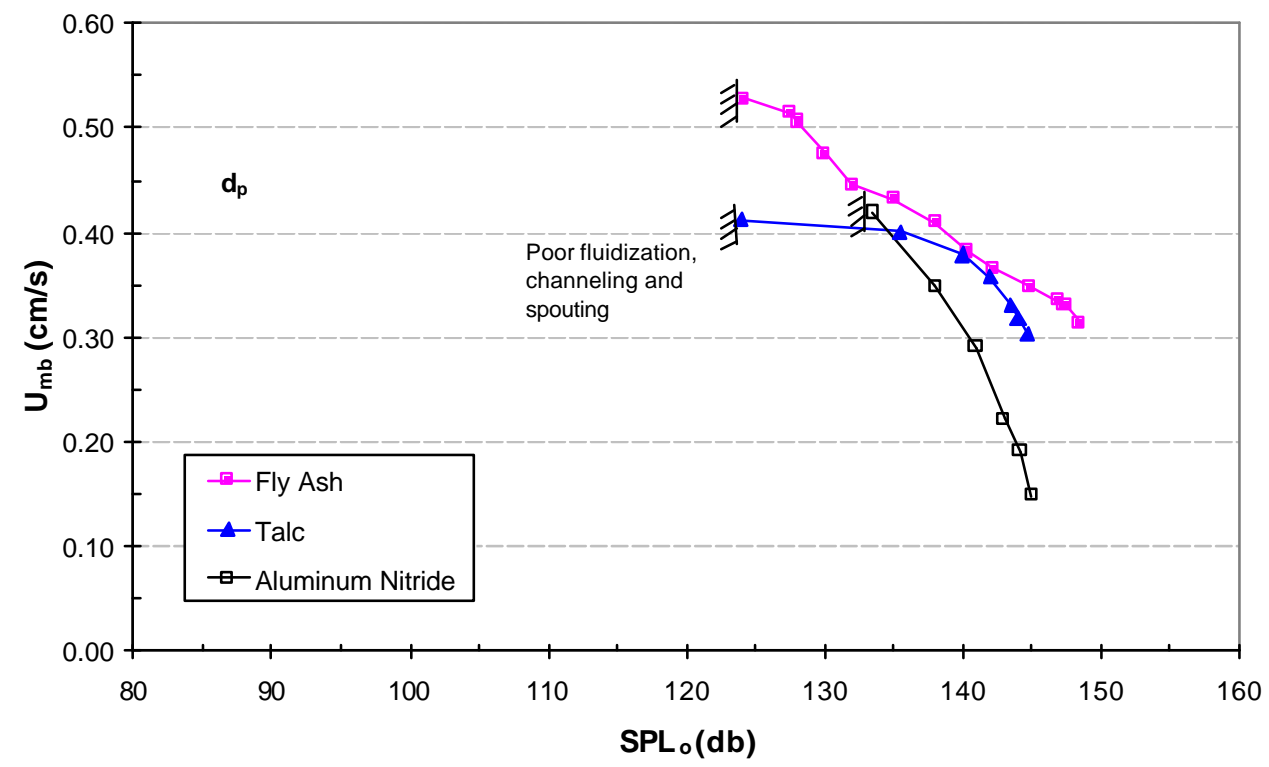

Figure 2: Variation of Minimum Bubbling Velocity with Sound Pressure Level. 
All of the fluidized bed experiments being performed in this project were carried out with acoustic excitation of the bed material. The activated carbon separation experiments were performed with mixtures of $A C$ and fly ash generated during a field trial at a pulverized coal power plant involving $\mathrm{Hg}$ capture using injected AC.

The separation experiments were carried out in a $15 \mathrm{~cm}$ diameter batch fluidized bed operating with room temperature air as the fluidizing gas. The bed has a porous plate distributor, is equipped with a loudspeaker above the freeboard, and is instrumented with a rotameter to measure air flow rate and a microphone to measure sound pressure level in the bed. The laboratory setup is similar to that illustrated in Figure 1.

Each separation experiment was performed by first loading the material into the bed vessel, turning on the sound and air flow, fluidizing at the desired operating conditions for several minutes, abruptly turning off the air and then the sound, and then carefully vacuuming out thin layers of the bed material, with each layer captured in a small filter bag (Figure 3). Each layer was then weighed and analyzed to determine total carbon content. The experiments were carried out with various air velocities to determine the combination of process conditions which yielded the sharpest separation.

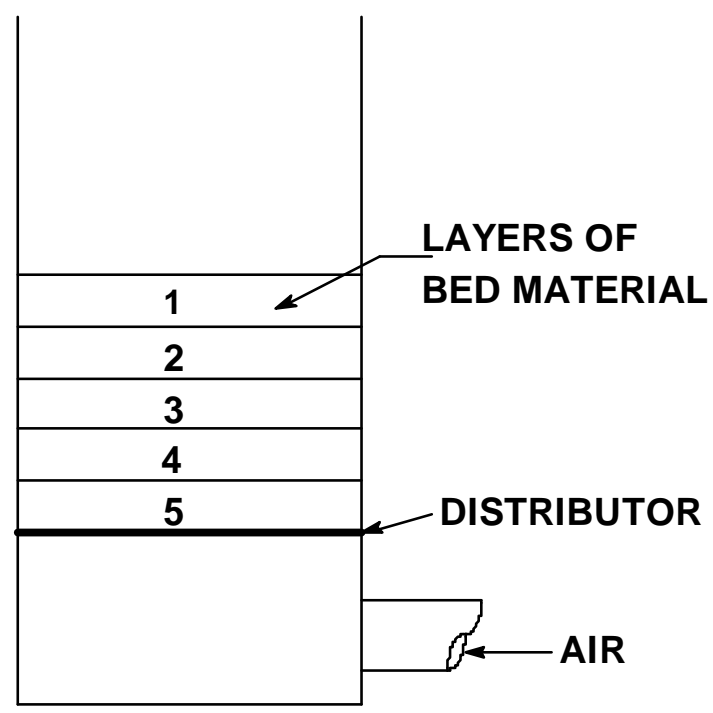

Figure 3: Sketch Showing Layering Technique for Analysis of Carbon Stratification in Fluidized Bed. 


\section{Task 2: Removal of Hg From Activated Carbon and Fly Ash}

In 1999, Hassett et al. (Ref. 7) reported on experiments in which samples of fly ash were tested for vapor phase $\mathrm{Hg}$ release in a thermal desorption apparatus. The Hassett study concluded that the temperatures at which most of the $\mathrm{Hg}$ was released ranged from about $230^{\circ} \mathrm{C}$ to close to $380^{\circ} \mathrm{C}$, depending on the nature of the fly ash and the predominant form of $\mathrm{Hg}$ on the ash. Similar desorption temperatures were reported by Biester and Zimmer (Ref. 8) for soil samples which had been contaminated by $\mathrm{Hg}$. More recently, Rubel et al. (Ref. 9) published data from $\mathrm{Hg}$ desorption experiments on fly ash and reported the $\mathrm{Hg}$ was released between 300 to $400^{\circ} \mathrm{C}$ for most samples.

This task is determining the potential for removing $\mathrm{Hg}$ from spent activated carbon and fly ash, using a heated bubbling fluidized bed. There is an extensive internal micropore structure in activated carbon, and the rate of $\mathrm{Hg}$ removal is likely to be limited by decomposition temperature and by mass transfer processes within the particles. The majority of fly ash particles are solid, having formed as molten ash solidifies in the colder sections of the boiler. As a consequence, the kinetics of $\mathrm{Hg}$ removal from fly ash is more likely controlled by decomposition temperature and mass transfer coefficient at the particle surface.

Gas fluidized beds operated with superficial gas velocities well in excess of minimum bubbling velocities are characterized by excellent gas-solid contacting, which results in high rates of both heat and mass transfer between gas and solids. Combined with the ability to fluidize fine particles with very low gas velocities (and, as a consequence, very low gas flow rates), the fluidized bed becomes the logical choice for removing $\mathrm{Hg}$ from the large volumes of ash and activated carbon which flow out of a boiler. $\mathrm{Hg}$ desorbed from the $\mathrm{AC}$ or ash will be in a highly concentrated form in the fluidizing gas and will be readily amenable to capture.

The $\mathrm{Hg}$ desorption experiments were performed in a $15 \mathrm{~cm}$ diameter batch fluidized bed equipped with an in-bed cylindrical electrical resistance heating element to raise the temperature of the bed material to temperatures in excess of $400^{\circ} \mathrm{C}$. As with 
the equipment used in the previous task, this bed is fluidized with air, and it has a loud speaker (acoustic speaker) above the bed vessel to allow acoustic excitation of the bed material. Thermocouples immersed in the bed were used to measure bed temperature, and air flow rate was measured with a rotameter.

The experimental procedure involved loading the material to be tested into the bed, turning on the loud speaker and the room temperature fluidization air, and then turning on the in-bed electrical heater. As the bed material gradually heated up, small samples of material were removed from the bed. This process was continued until the maximum desired temperature was reached. After being cooled, the samples were analyzed for Hg content using a LECO Advanced Mercury Analyzer, which uses an atomic absorption spectrophotometer for detection of $\mathrm{Hg}$ concentrations.

\section{Task 3: Microstructural and Chemical Analysis of Fly Ash and Activated Carbon}

The experiments in Tasks 1 and 2 required microstructural and spectroscopic analysis of fly ash and AC samples. Specimens of fly ash and AC produced by the Task 1 separation experiments were subjected to some or all of the following types of analyses:

- Light Optical Microscopy Analysis of Fly Ash and Activated Carbon - Light Optical Microscopy is a powerful tool useful for visualizing surface features. Although an optical microscope is not powerful enough to visualize particles in the micron size range and under, it still provides a simple and direct tool to examine the macroscopic features of the fly ash and activated carbon particles.

Black and white images were taken with the camera attached to a Nikon Metaphot photo micrographic microscope. Objective lenses of $5 \mathrm{X}, 10 \mathrm{X}, 20 \mathrm{X}$ and 50X were used in order to obtain the desired magnification levels when imaging fly ash and activated carbon particles.

- Particle Identification by Morphological Observation-Scanning Electron Microscopy (SEM) of particle samples was carried out using an FEI XL30 
environmental scanning electron microscope equipped with an EDS spectrometer. By this means, it was possible to distinguish the various particle types by point EDS analyses and by utilizing the fact that the fly ash contains $\mathrm{Si}, \mathrm{Fe}, \mathrm{S}$ and $\mathrm{Al}$ in addition to $\mathrm{C}$ and $\mathrm{Hg}$.

- TEM Analysis of the Fly Ash/AC Mixtures - Samples of the fly ash/AC powders were dry dispersed and supported on holey carbon films for TEM examination. A 200kV JEOL 2000FX TEM, which is equipped with EDS and EELS, was used for the analysis. A combination of high resolution imaging, electron diffraction and EDS point analyses was used to characterize the mineral constituents that make up the rapidly solidified fly ash particles, which contain silica, alumina and iron sulfites and unburnt carbon. We also attempted to use EDS analysis to determine whether $\mathrm{Hg}$ is preferentially associated with any of these phases or if it is uniformly distributed on the surface of the fly ash. However the Hg levels of the samples examined were below the EDS detectability limit of the instrument.

- Microanalysis of the $\mathrm{AC}-\mathrm{A}$ combination of high resolution electron microscopy (HREM) and EELS in the JEOL 2000FX TEM was explored as a possible way to structurally characterize the porosity and structure of the AC. If the $\mathrm{Hg}$ is atomically dispersed throughout the $\mathrm{AC}$ network structure, then it will be impossible to image. If, however, the $\mathrm{Hg}$ segregates to form $\mathrm{nm}$ scale particulates either on or within the AC, z-contrast ADF imaging in the TEM may allow us to detect their presence.

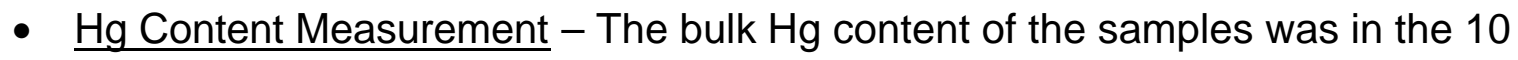
to $30 \mathrm{ppm}$ range, so a rather sensitive quantitative composition analysis technique was required. A LECO Atomic Absorption Spectroscopy (AAS) analyzer was used to quantitatively compare the $\mathrm{Hg}$ content of fly ash and $\mathrm{AC}$ samples before and after thermal treatment, in order to assess the effectiveness of $\mathrm{Hg}$ removal.

- Surface Chemistry Analysis - X-ray Photoelectron Spectroscopy (XPS) in a Scienta ESCA instrument was used to study the surface chemistry of a small selection of samples. For example, comparative studies of the surface 
composition of samples before and after SCR were used to look for

systematic variations in the surface $\mathrm{Cl}$ and $\mathrm{S}$ content. Furthermore, $\mathrm{Hg}$ contaminated samples were analyzed in an effort to determine if the $\mathrm{Hg}$ was segregated at the material surface.

\section{Task 4: Effect of SCR on Ash Properties}

The analyses performed in this task attempted to determine if the presence of an SCR catalyst affects those fly ash properties which are important for $\mathrm{Hg}$ capture.

Samples of fly ash for these analyses were obtained from two power plants equipped with SCR reactors. In one case, fly ash had been obtained by sampling isokinetically across the gas duct both upstream and downstream of the SCR reactor. At the second power plant, there are four coal-fired boilers of identical design, with two equipped with SCR reactors. All four burned the same coal. Samples of fly ash were obtained from the electrostatic precipitator hoppers downstream of the air preheaters. The fly ash samples were analyzed for unburned carbon, mineral constituents, surface chemical composition and total $\mathrm{Hg}$ content. It was expected that any significant differences in surface chemical composition would provide clues to the role of fly ash properties in the $\mathrm{Hg}$ capture process and in the possible effects of the SCR reactor. 


\section{RESULTS AND DISCUSSION}

\section{Separation of Activated Carbon and Fly Ash in a Fluidized Bed}

Experiments were performed with mixtures of activated carbon and fly ash (AC/fly ash) to determine to what extent the activated carbon and naturally occurring carbon in the ash can be separated from the inert portions of the fly ash. The AC/fly ash mixture had been collected in a baghouse at the back end of a pulverized coal boiler. The mixture had an average carbon content of approximately 22 percent and an average $\mathrm{Hg}$ concentration of approximately $14 \mathrm{ppm}$. The activated carbon injected into the boiler was 70 percent carbon and 30 percent inert materials. No information was provided on the ratio of $A C$ to fly ash entering the baghouse nor on the unburned carbon content of the fly ash.

The experiments were carried out at room temperature in the $15 \mathrm{~cm}$ diameter fluidized bed equipped with an acoustic speaker (loud speaker) positioned at the top of the bed vessel. The settled bed depth was $8 \mathrm{~cm}$ and the sound pressure level at the distributor was $140 \mathrm{db}$. The superficial velocity of the fluidizing air was varied from 0.6 to $1.1 \mathrm{~cm} / \mathrm{s}$.

In each experiment, the bed was fluidized for approximately 10 minutes to assure steady state conditions, and the fluidizing air was then abruptly turned off. As described in the previous section, the bed material was then removed from the bed, layer by layer.

The data plotted in Figures 4 to 9, show how the carbon content of the bed material varied with vertical distance from the distributor, when the bed was fluidized at different velocities. These show the largest segregation occurred at superficial velocities of 0.7 to $0.8 \mathrm{~cm} / \mathrm{s}$. At these conditions, the carbon content at the top of the bed was approximately 27 percent and it was less than 15 percent in the bottom layer. Very little or no carbon segregation occurred at velocities much lower than 0.7 to 0.8 $\mathrm{cm} / \mathrm{s}$ or higher than $1.0 \mathrm{~cm} / \mathrm{s}$ (Figure 10). It should be noted that the carbon is a mixture of $A C$ and naturally occurring unburned carbon from the fly ash. These are both referred to here as "carbon." 


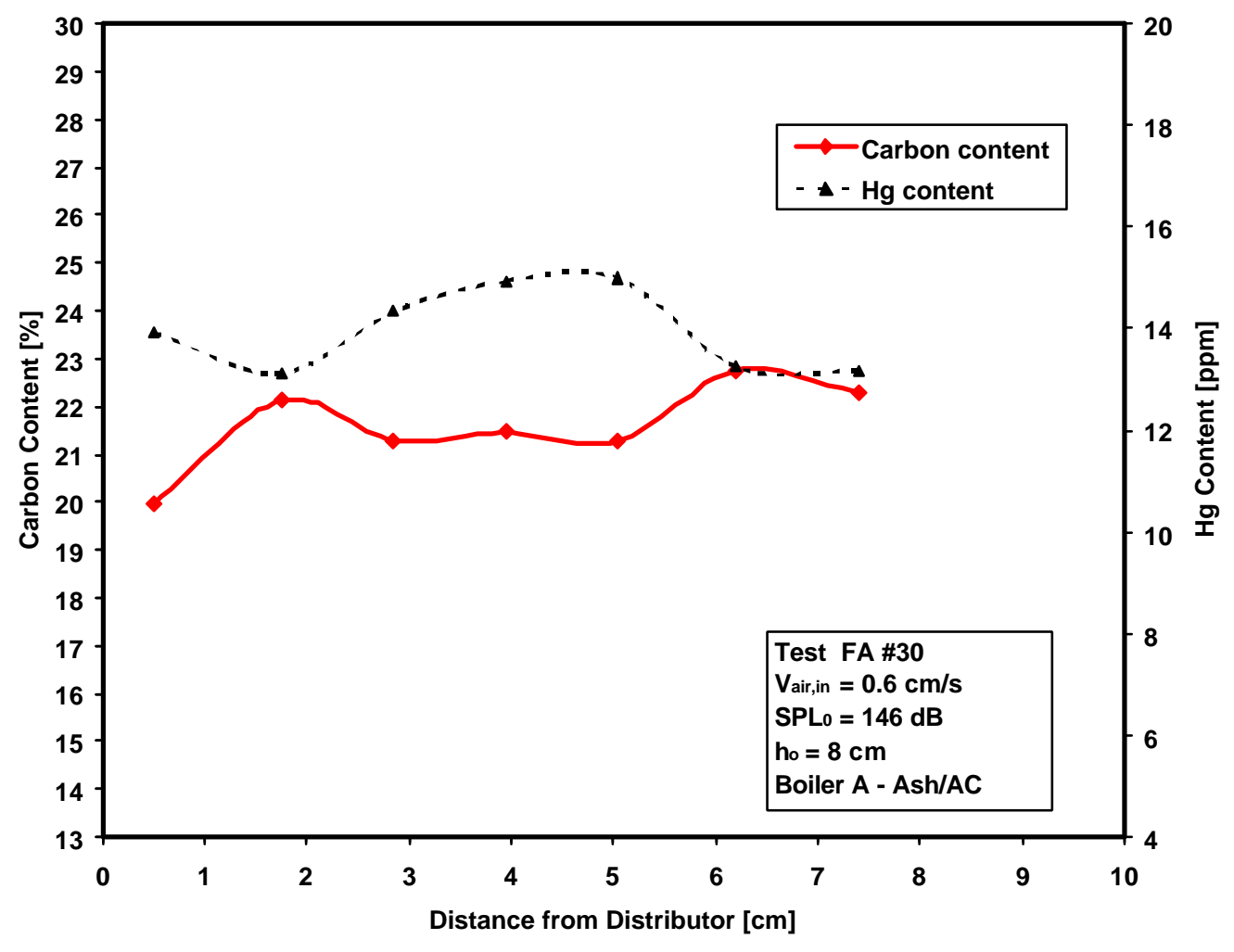

Figure 4: Vertical Stratification of Carbon and Hg. $V_{\text {air }}=0.6 \mathrm{~cm} / \mathrm{s}$.

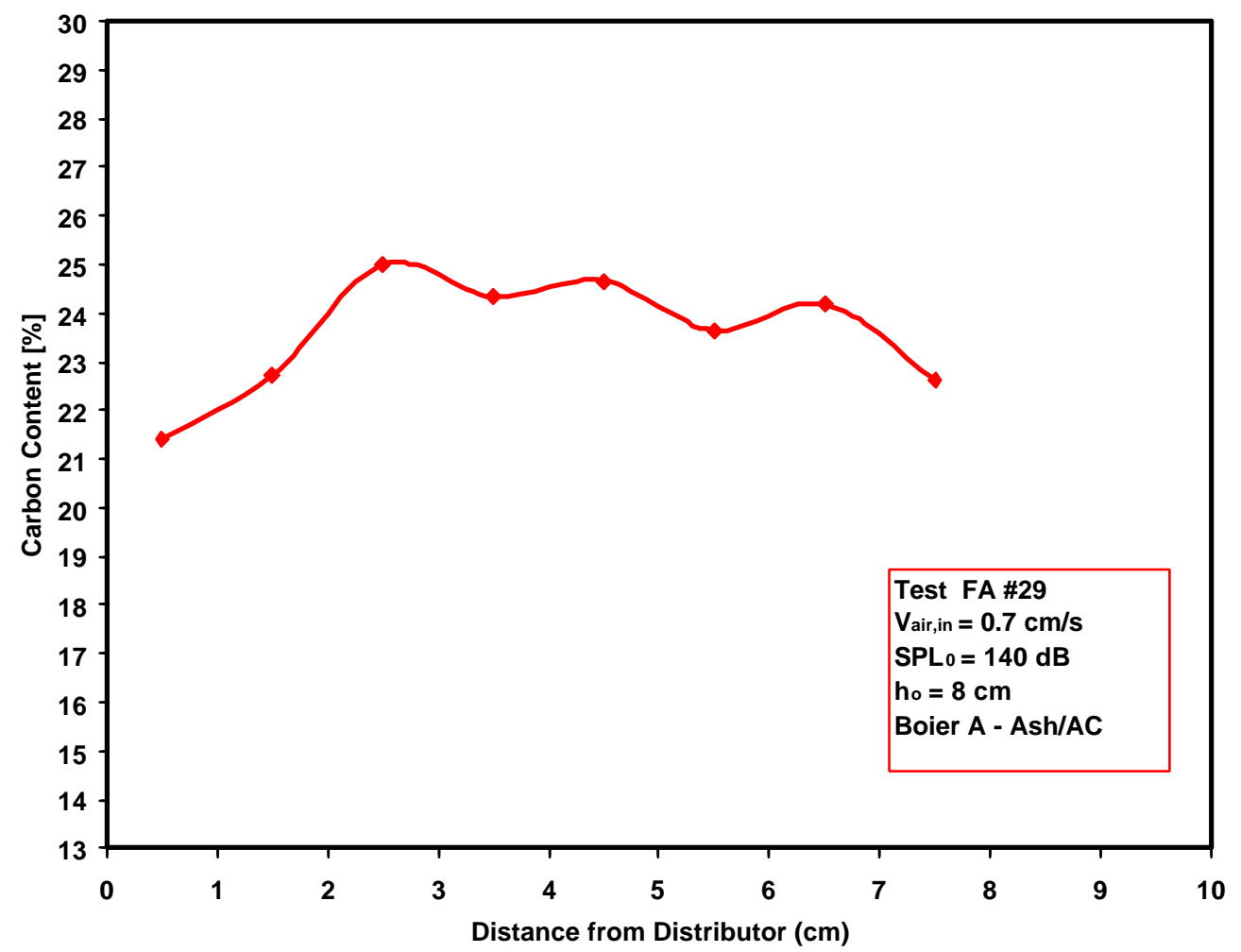

Figure 5: Vertical Stratification of Carbon. $V_{\text {air }}=0.7 \mathrm{~cm} / \mathrm{s}$. 


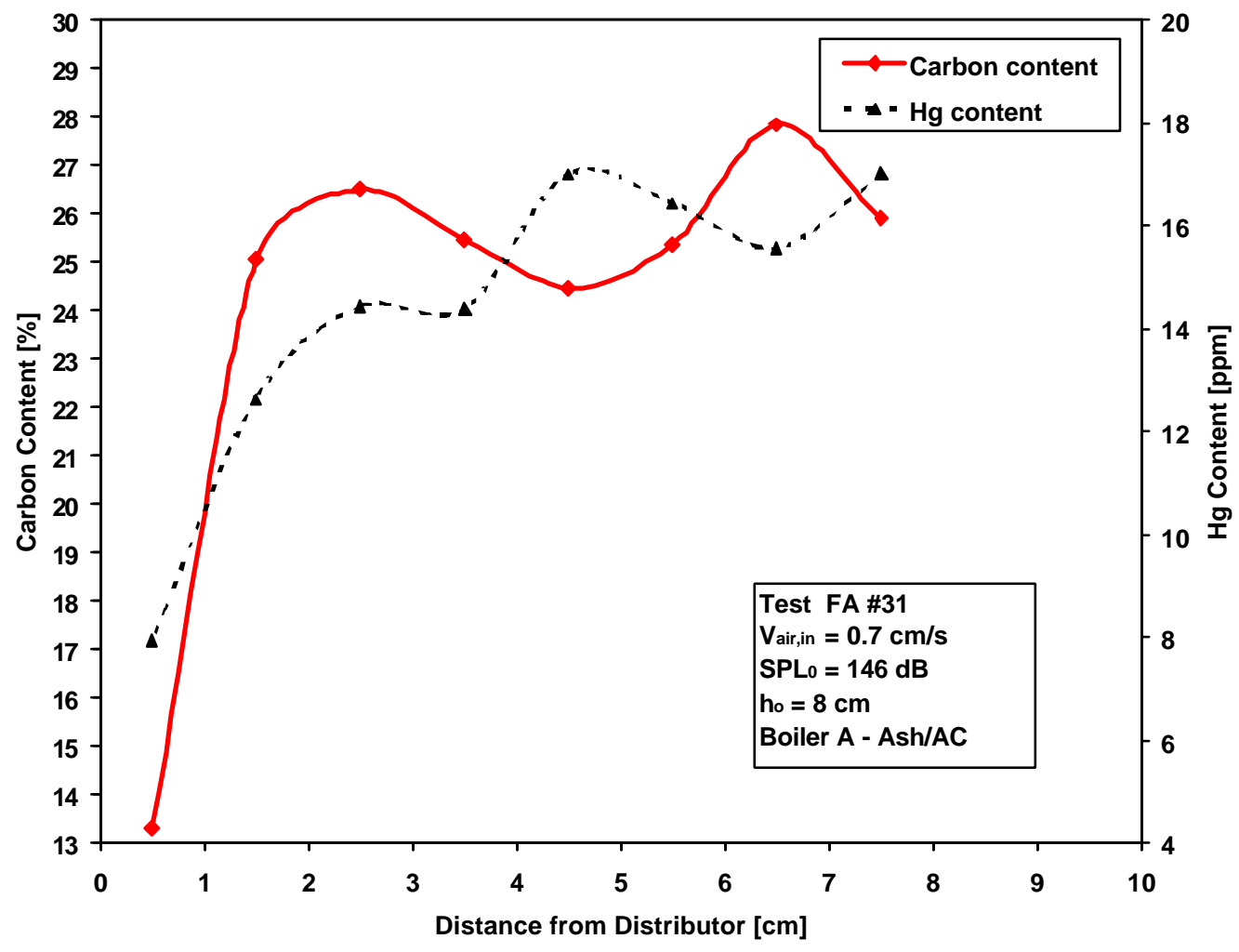

Figure 6: Vertical Stratification of $\mathrm{Hg}$ and Carbon. $\mathrm{V}_{\text {air }}=0.7 \mathrm{~cm} / \mathrm{s}$.

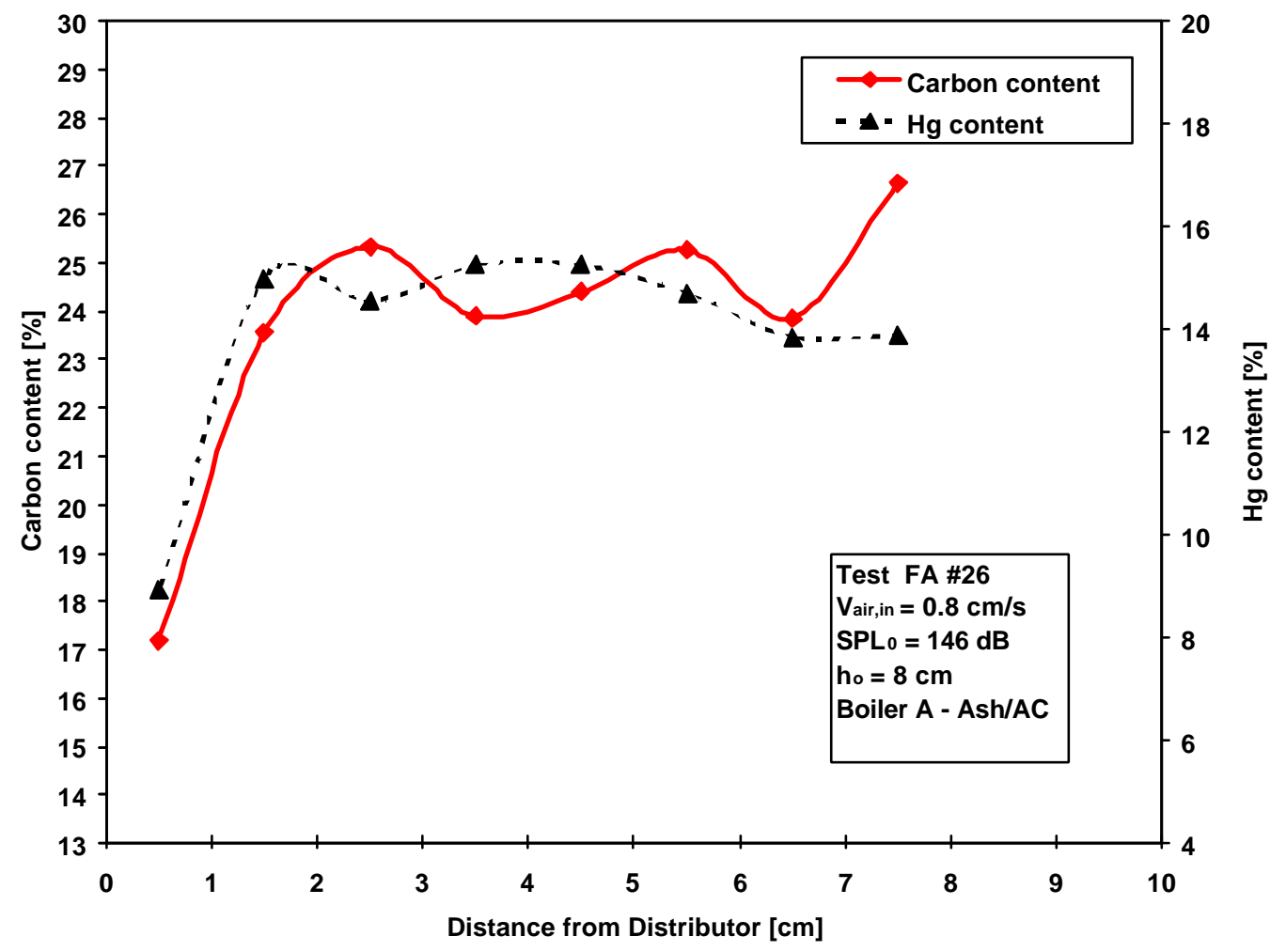

Figure 7: Vertical Stratification of $\mathrm{Hg}$ and Carbon. $V_{\text {air }}=0.8 \mathrm{~cm} / \mathrm{s}$. 


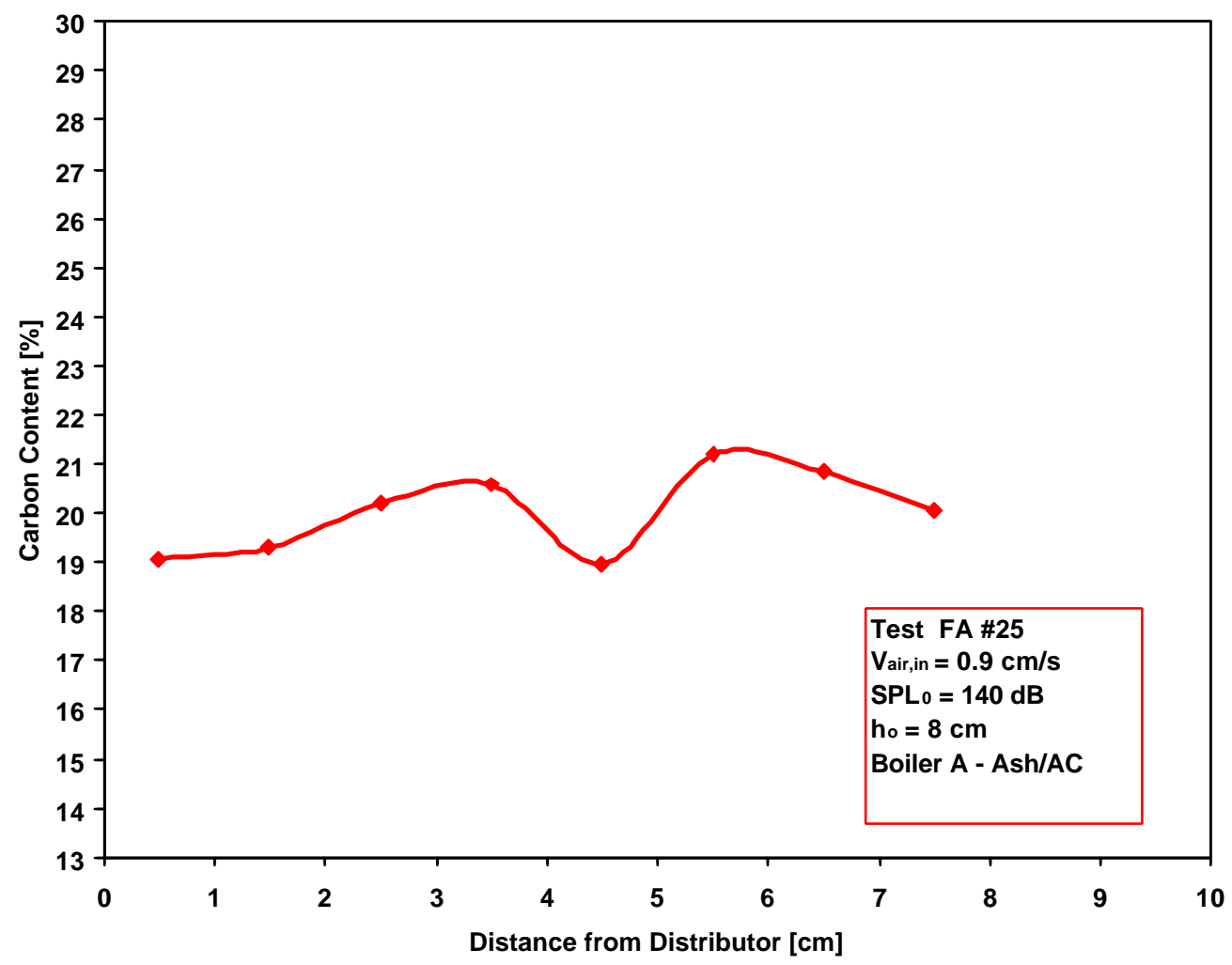

Figure 8: Vertical Stratification of Carbon. $V_{\text {air }}=0.9 \mathrm{~cm} / \mathrm{s}$.



Figure 9: Vertical Stratification of Carbon. $V_{\text {air }}=1.1 \mathrm{~cm} / \mathrm{s}$. 


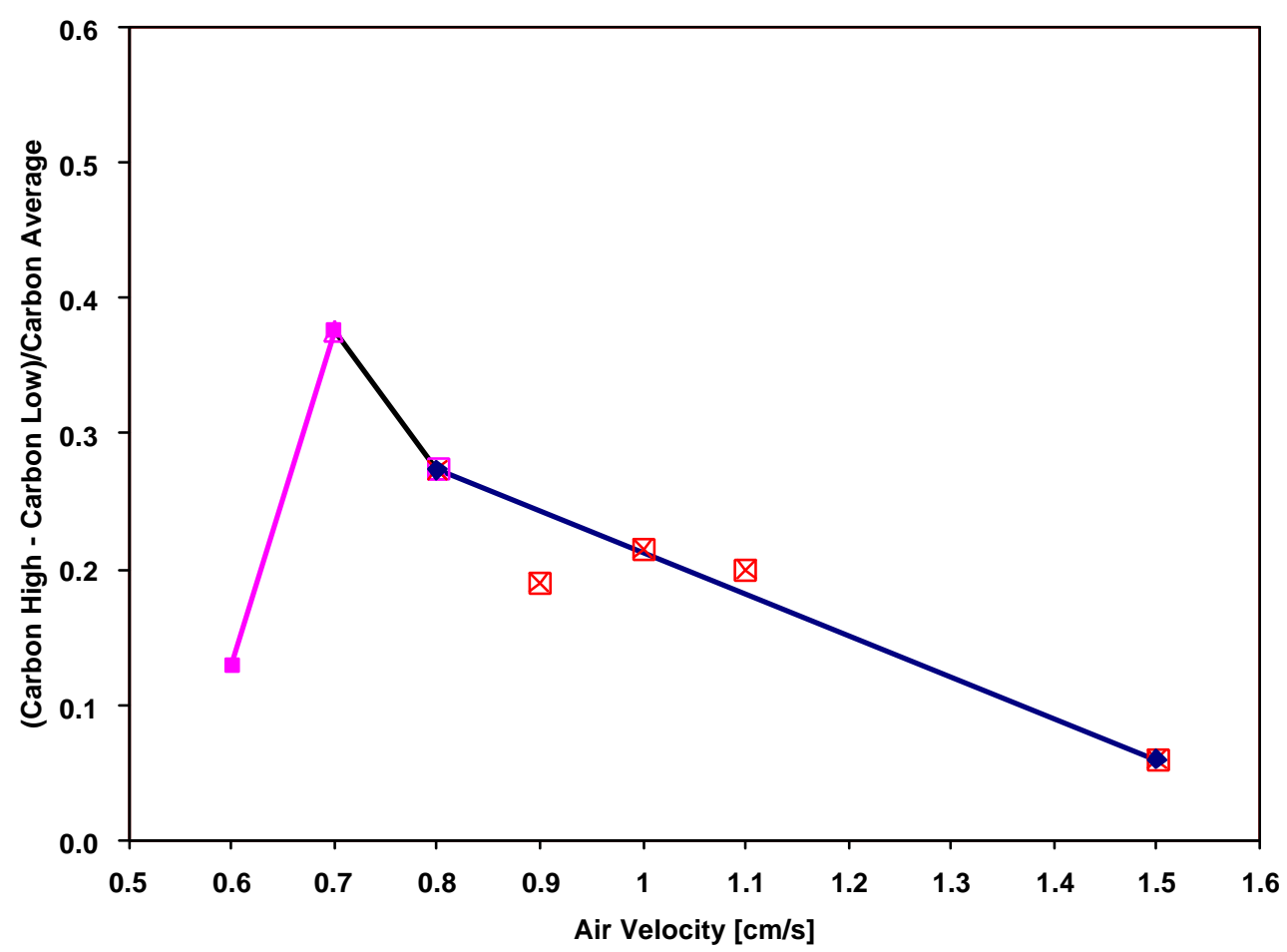

Figure 10: Magnitude of Carbon Stratification Versus Superficial Air Velocity.

Fluidized bed particle segregation, based on particle density and size is controlled by bubbling in the bed. At velocities close to minimum bubbling, there is insufficient bubbling to transport the low-density particles towards the free surface and the high-density particles towards the distributor. At much higher velocities, the bubbling is much more intense, and this maintains the bed material in a well-mixed state and prevents particle segregation. Figure 11 shows the minimum fluidization velocity as determined from bed pressure drop experiments was approximately $0.8 \mathrm{~cm} / \mathrm{s}$. The minimum bubbling velocity is close to $U_{m f}$ in magnitude. The optimal fluidization velocity will vary depending on the size and density distribution of the particles.

Using the LECO Analyzer, samples of AC/Ash obtained from the various layers of the bed were also analyzed for $\mathrm{Hg}$ content. Figure 12 summarizes the $\mathrm{Hg}$ data in a graph of $\mathrm{Hg}$ content vs. carbon level. This figure shows very clearly the strong dependence of $\mathrm{Hg}$ content on carbon content, with the $\mathrm{Hg}$ content approaching zero as LOI (carbon) approaches zero. 


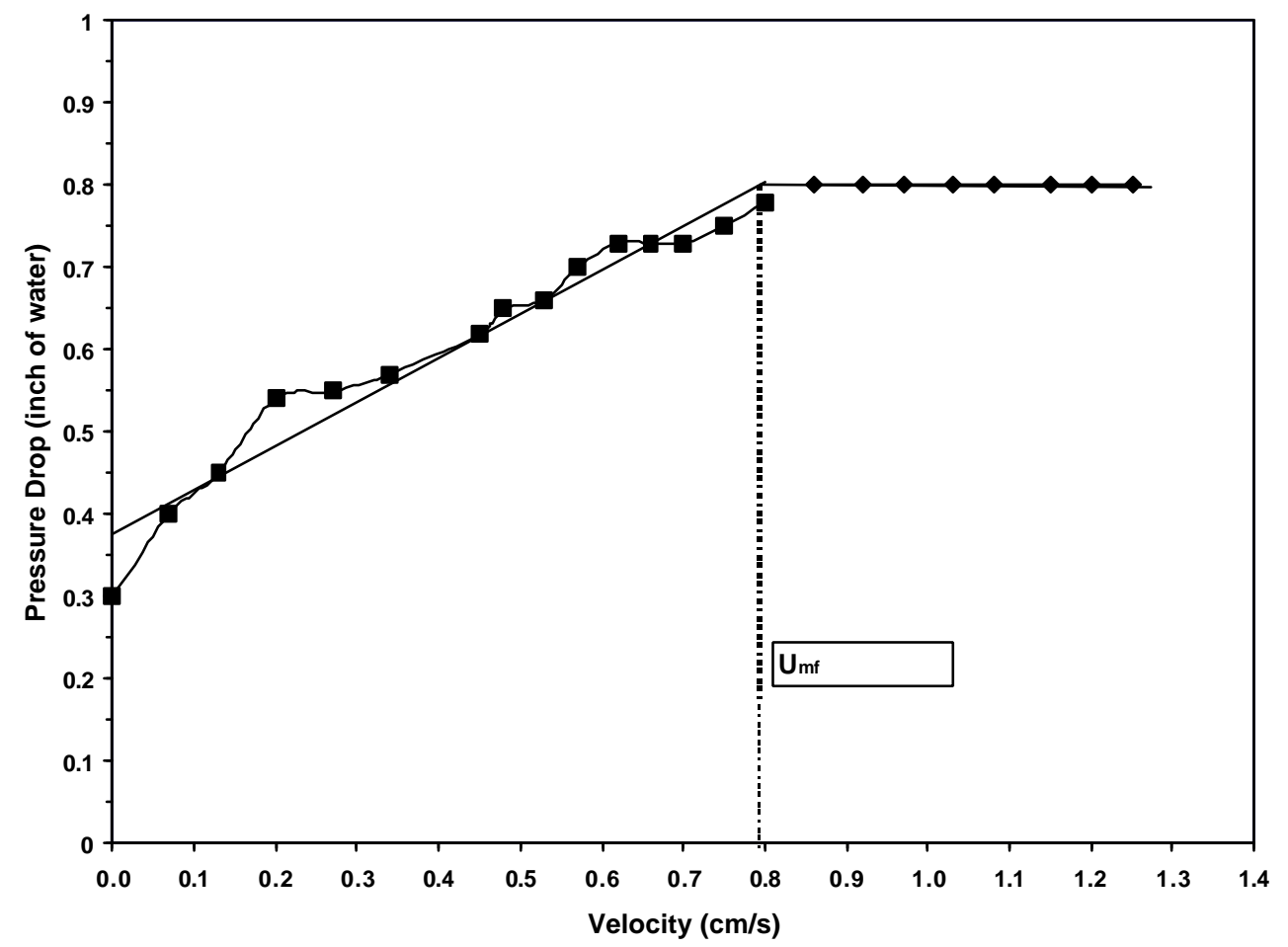

Figure 11: Minimum Fluidization Velocity From Bed Pressure Drop Test.

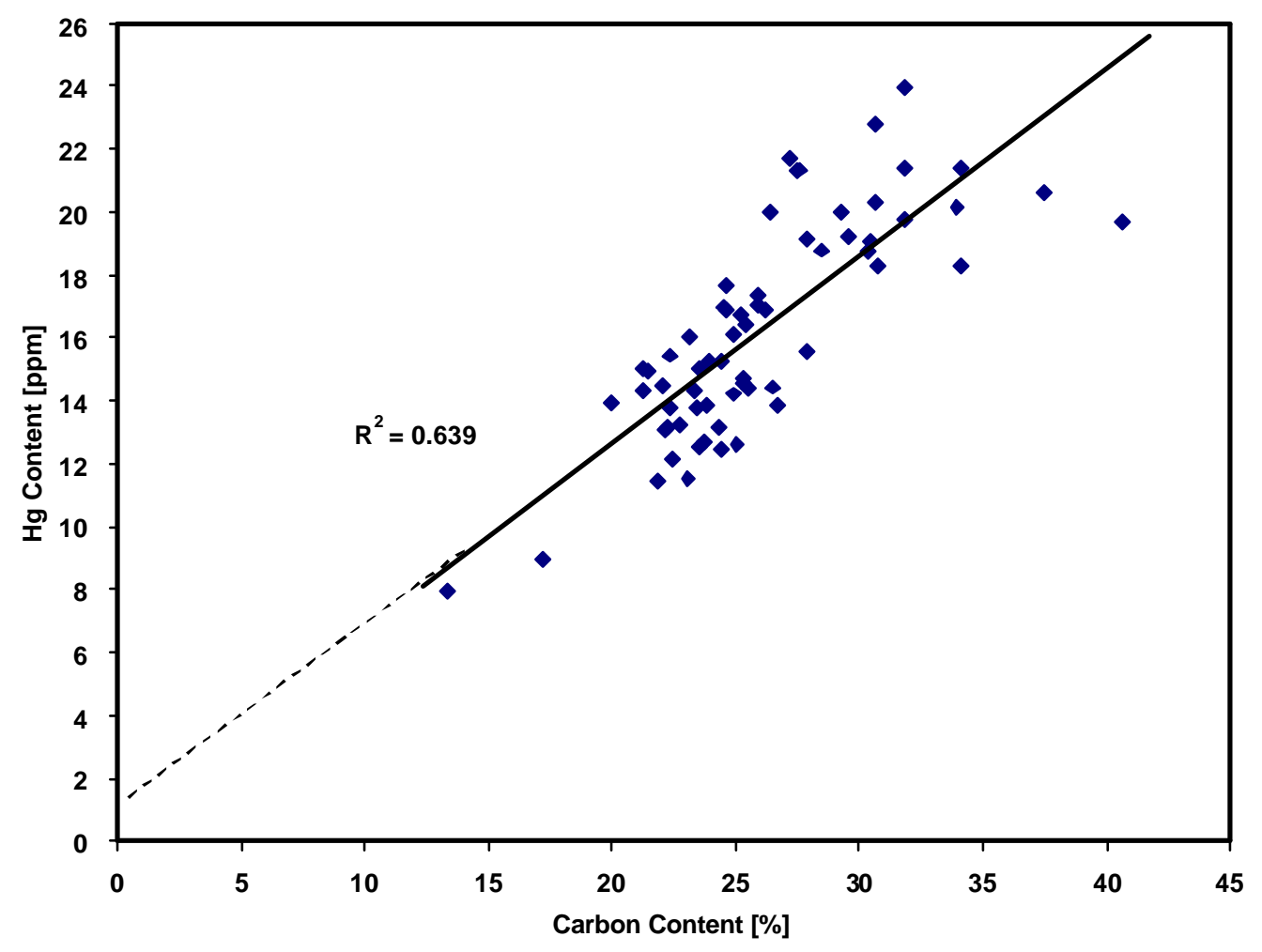

Figure 12: Hg Versus Carbon Content. 


\section{Removal of $\mathrm{Hg}$ from Activated Carbon and Fly Ash}

Experiments were performed with the AC/ash mixture used in Task 1 to determine the temperature at which $\mathrm{Hg}$ is driven from the mixture. These experiments were performed in the heated fluidized bed, using the procedure described in the "Experimental" section. Once the bed was fluidized and the electrical heater turned on, an experiment lasted from one to 1.5 hours. As the temperature of the bed gradually increased with time, small samples of bed material were removed from the bed and analyzed for $\mathrm{Hg}$ content using the LECO Hg Analyzer.

Figures 13, 15 and 17 each depict fluidized bed temperature distributions along the air flow direction using bed material from different elevations in the segregated fluidized bed. Each test represents a different carbon content of fly ash/activated carbon mixture. This includes 32.6 carbon from the top layers of the bed during segregation tests, 24.8 percent from as-received ash samples and 17.3 percent LOI from the bottom layers of the bed.

It can be seen from the bed temperature curves that the bottom two thermocouple readings (TC \#8 and TC \#10) were always in agreement with each other. The other four thermocouple readings decreased in the direction of air flow; with TC \#1, which is located above the bed, giving significantly lower readings than the others. The average of the bottom five thermocouple (TC \#4, 5, 7, 10 and 8) readings was used as the indication of the bed material temperature during the test. The tests usually lasted 50 minutes and the highest temperatures reached were near $500^{\circ} \mathrm{C}\left(932^{\circ} \mathrm{F}\right)$.

Figures 14, 16, and 18 illus trate the relationships between bed temperature and $\mathrm{Hg}$ content of the different bed materials. The error bars indicate the $+/-2$ sigma uncertainty in the $\mathrm{Hg}$ values, caused by a combination of sampling and measurement errors. These results show that, within the accuracy of the data, the $\mathrm{Hg}$ content was constant during the initial part of the heating process, with the $\mathrm{Hg}$ content decreasing at higher temperatures. When the bed temperature was near $500^{\circ} \mathrm{C}\left(932^{\circ} \mathrm{F}\right)$, the $\mathrm{Hg}$ content was close to zero. The temperature at which the $\mathrm{Hg}$ content began to decrease 


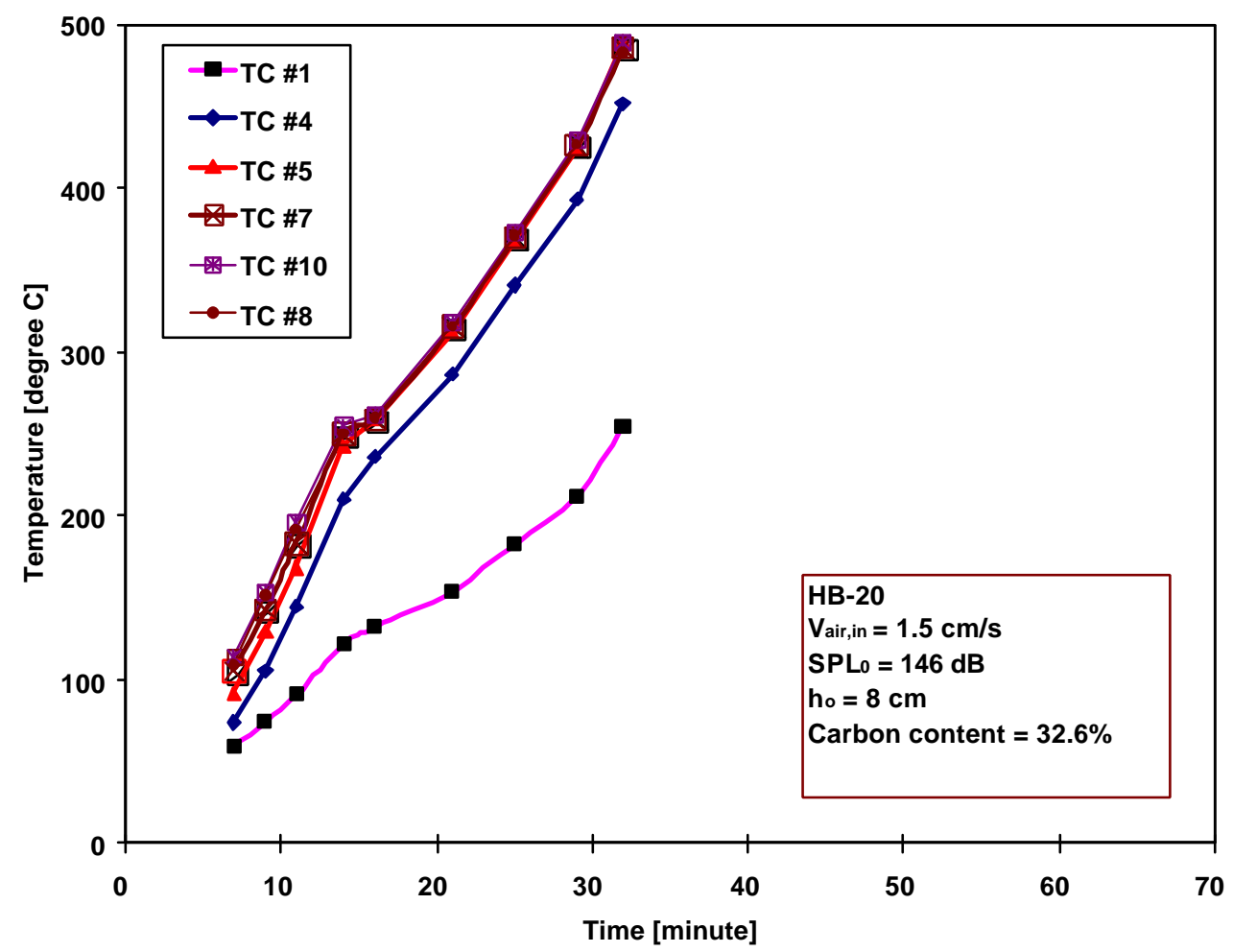

Figure 13: Bed Temperature Versus Time (High Carbon).

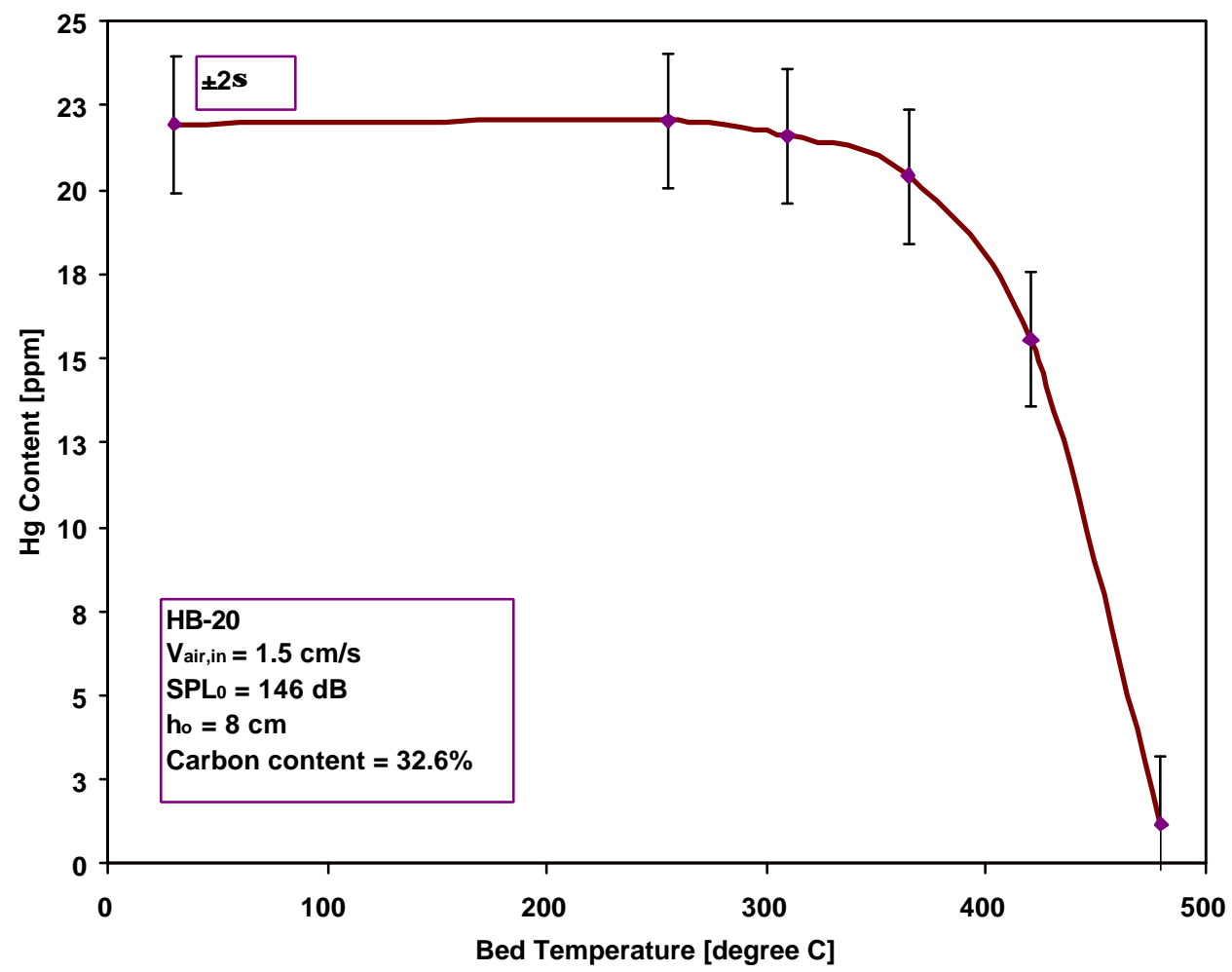

Figure 14: Hg Content Versus Bed Temperature (High Carbon). 


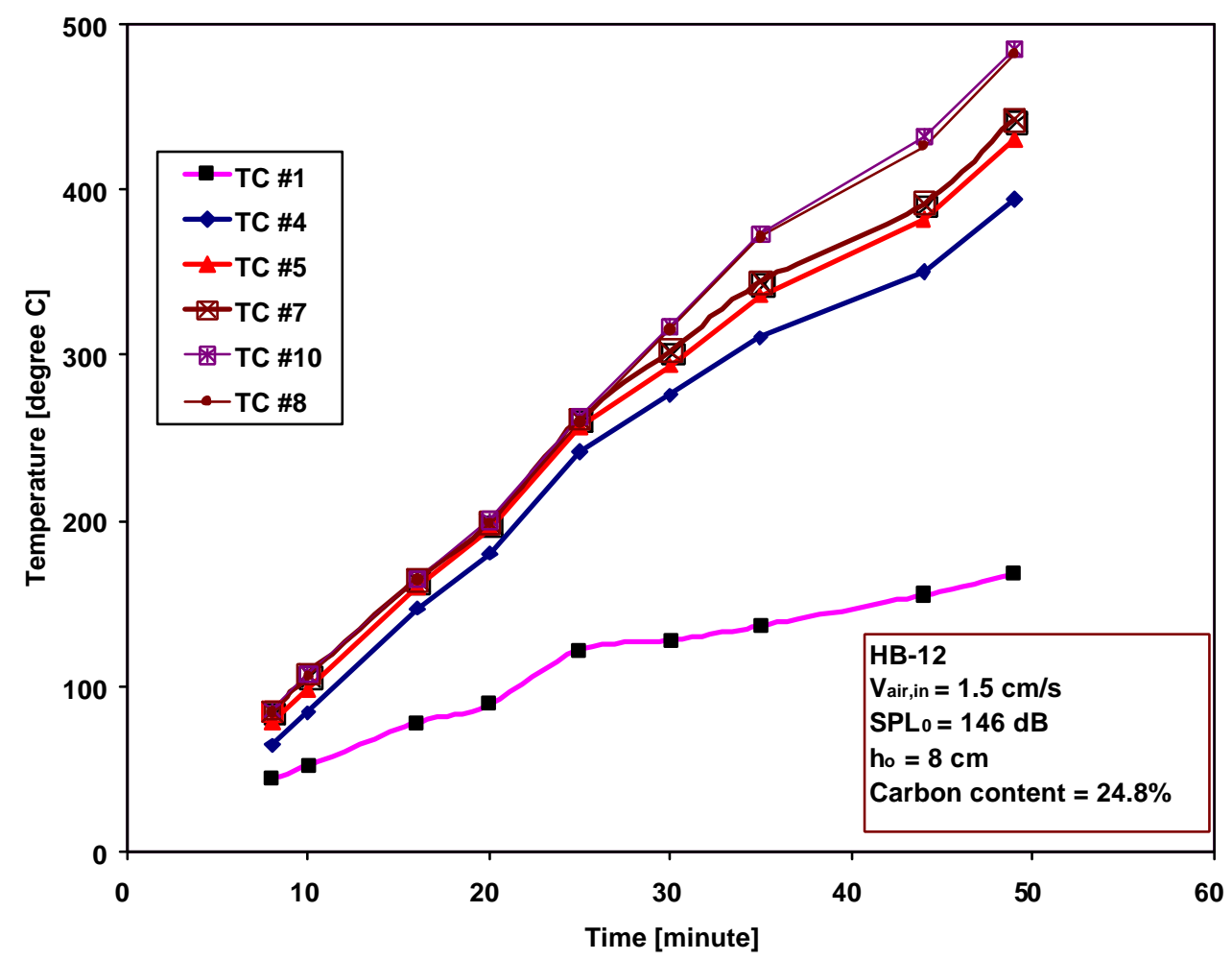

Figure 15: Bed Temperature Versus Time (Medium Carbon).

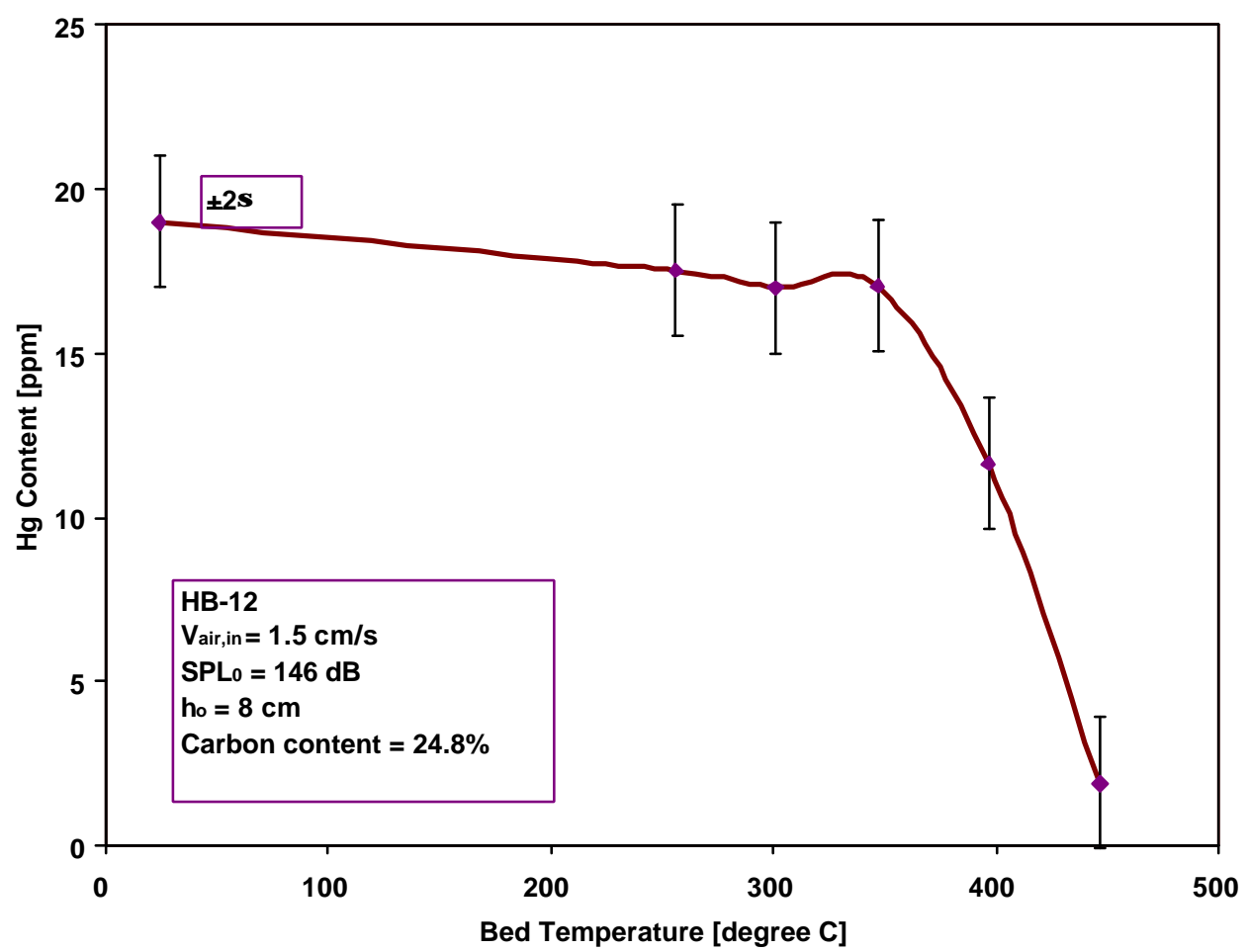

Figure 16: Hg Content Versus Bed Temperature (Medium Carbon). 


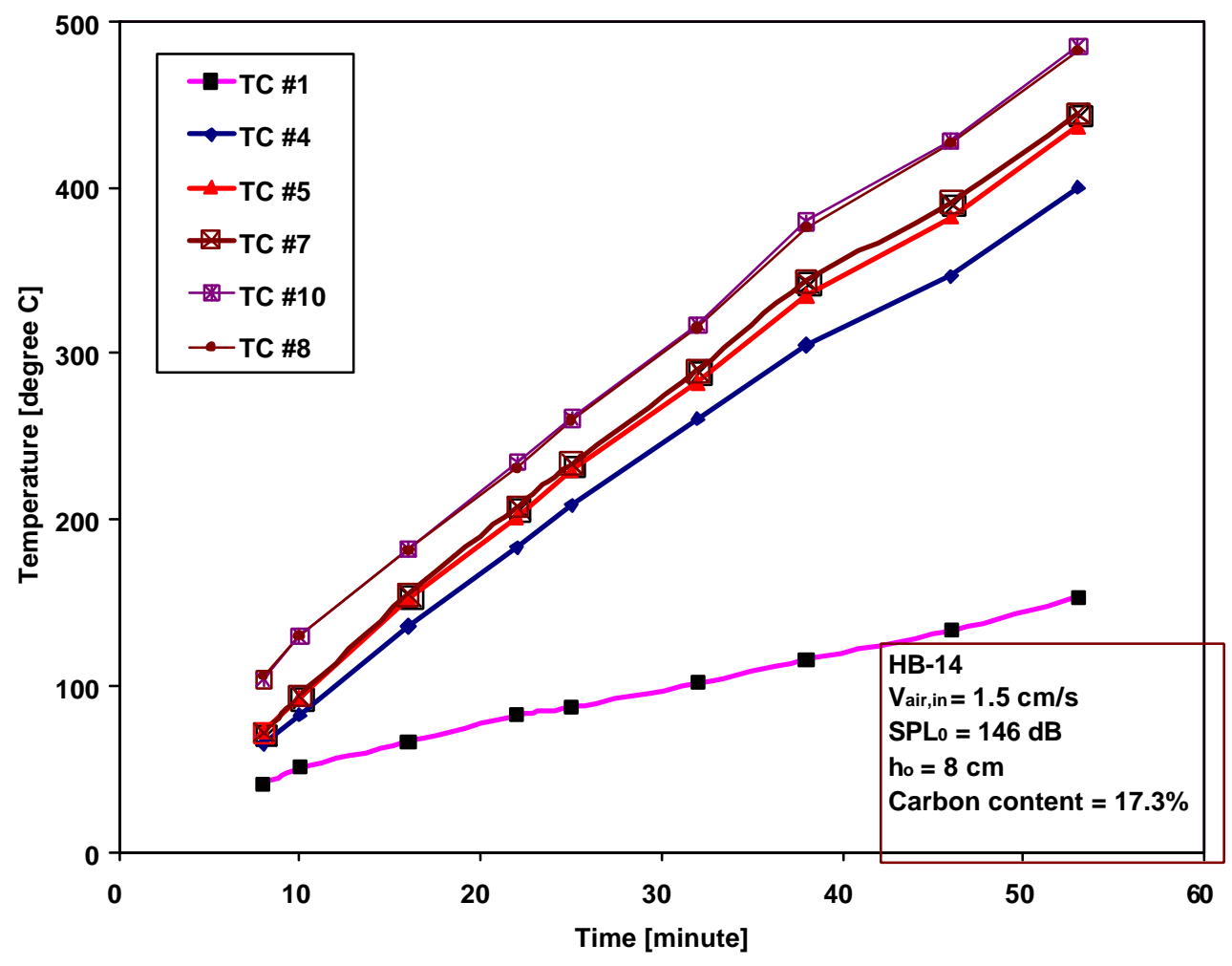

Figure 17: Bed Temperature Versus Time (Low Carbon).

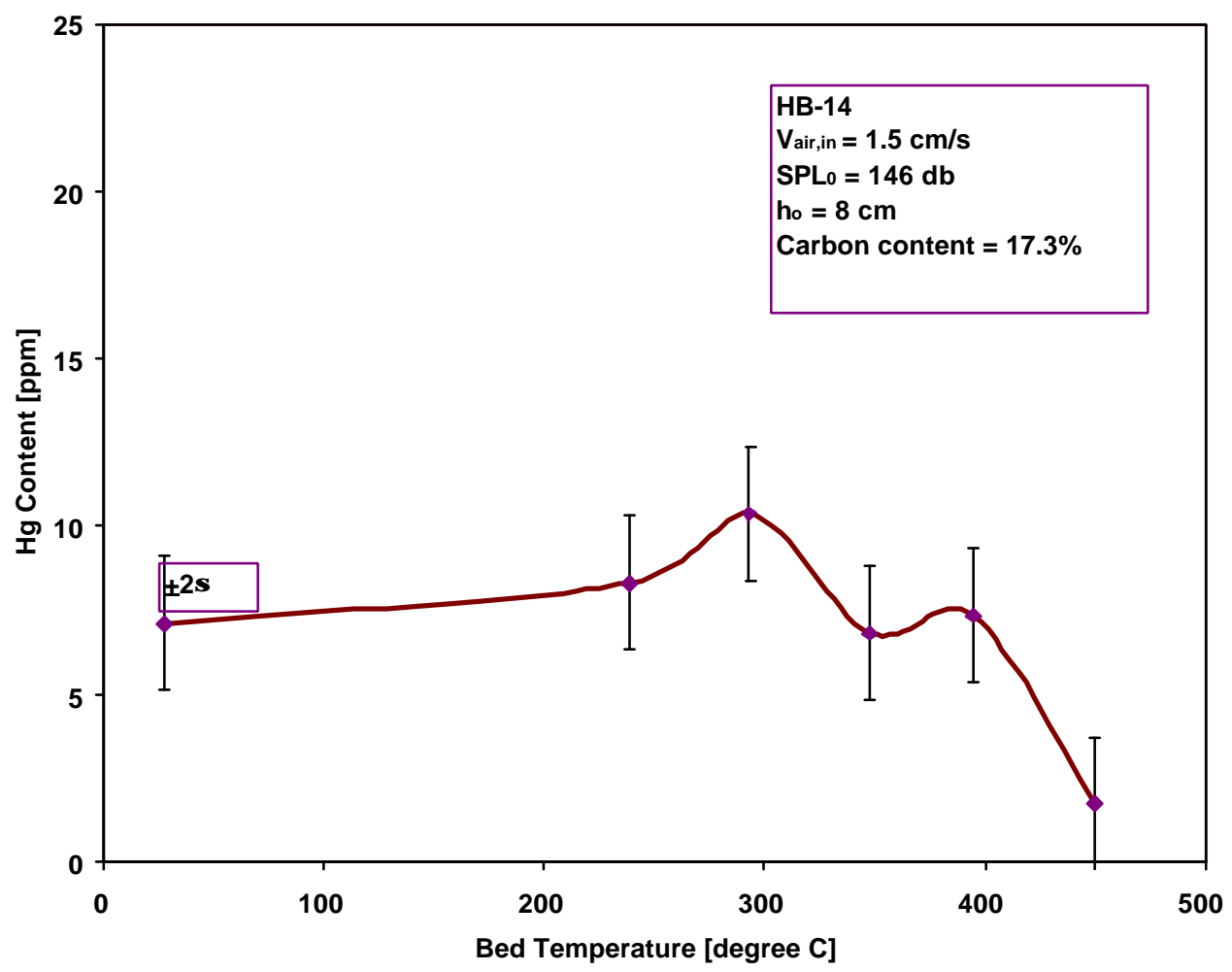

Figure 18: Hg Content Versus Bed Temperature (Low Carbon). 
is defined as the "critical" temperature. Figure 19 shows a linear relationship between critical temperature and carbon content, with the critical temperature ranging from 330 to $370^{\circ} \mathrm{C}$. Figure 19 also shows the bed temperature when the $\mathrm{Hg}$ content decreased to zero was between $450^{\circ} \mathrm{C}\left(842^{\circ} \mathrm{F}\right)$ and $500^{\circ} \mathrm{C}\left(932^{\circ} \mathrm{F}\right)$.

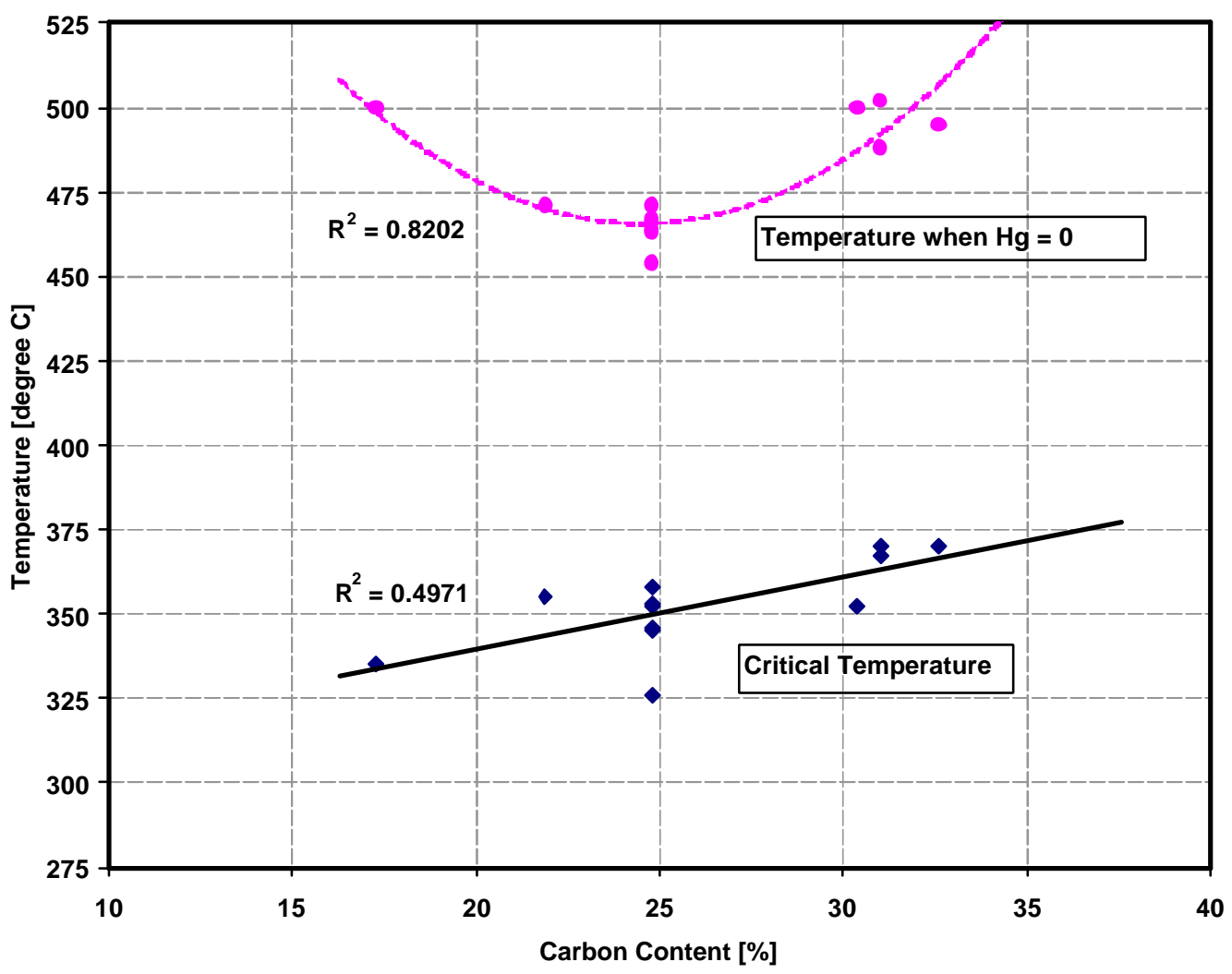

Figure 19: Critical Temperature Versus Carbon.

\section{Morphology of Fly-Ash/Activated Carbon Mixtures}

\section{General Characteristics}

The fly ash/activated carbon sample used in this study was chosen as a representative material on which to commence our structural characterization studies. Figure 20 shows a typical low magnification SEM micrograph of the fly ash sample in which a diverse range of morphologies and particle sizes can be observed. The sample was examined by both SEM and TEM in an attempt to gain the ability to recognize the particle types present. Four main types of particles were identified. The first characteristic morphology shown in Figure $21 \mathrm{a}$ is of large $(30-100 \mu \mathrm{m})$ irregular shaped particles that were identified by EDS (Figure 21 b) to be essentially carbon or charcoal. 


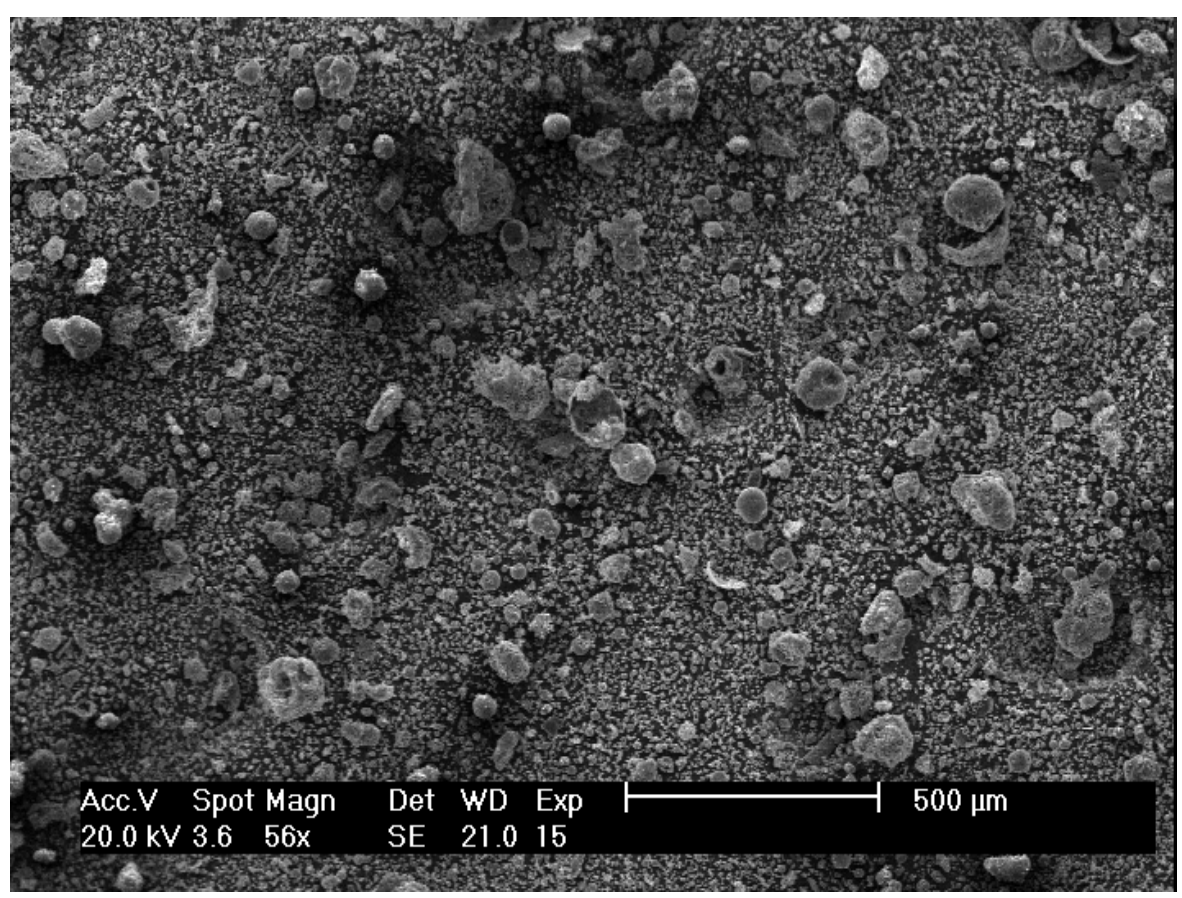

Figure 20: Low Magnification SEM Micrograph of a Fly Ash/AC Sample from Boiler A. Note the Diverse Range of Particle Sizes and Microstructures That Can Co-Exist.
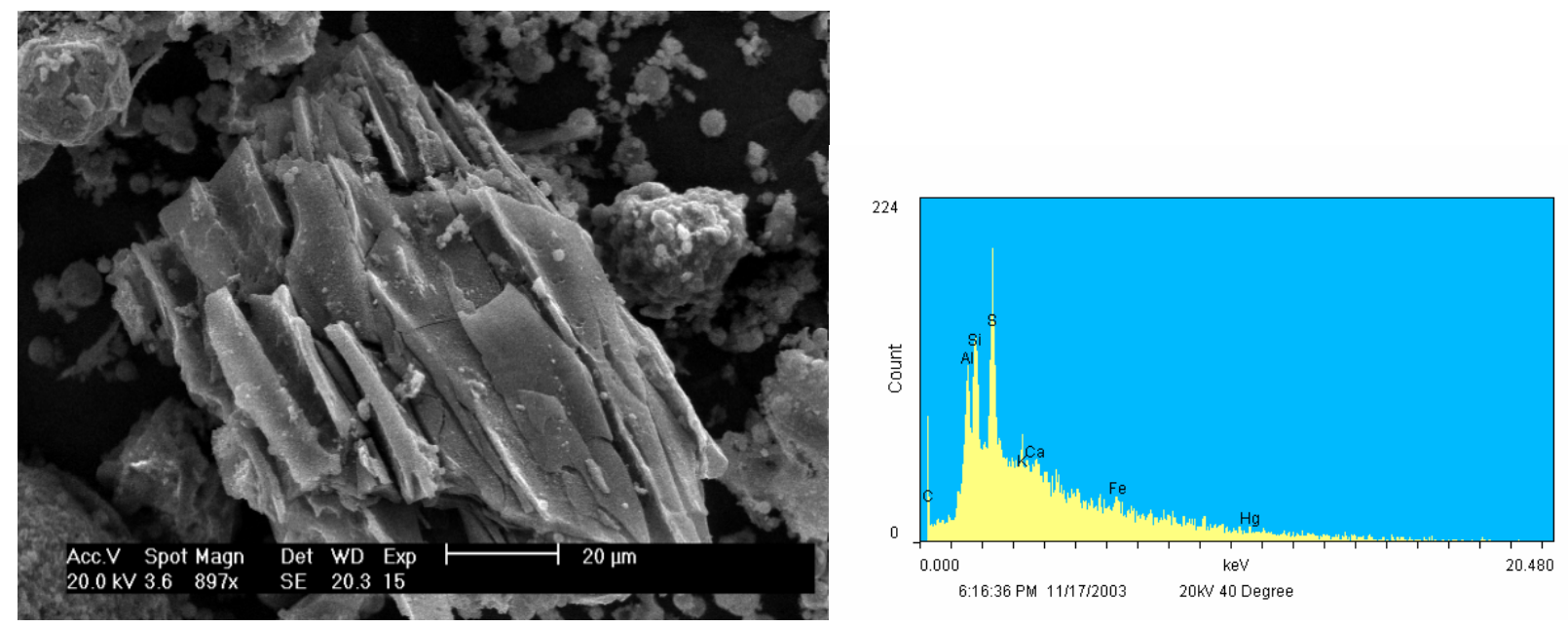

Figure 21: SEM Micrograph (a) and EDS Spectrum (b) From a Typical Particle of Unburnt Carbon. 
A second very characteristic morphology is that of spherical particles that have a hierarchy of sizes ranging from 0.1 to $20 \mu \mathrm{m}$ in diameter, as shown in Figure 22a. The surface of these spheres is always decorated with fine 'debris' of another material. EDS spectra from these spheres (Figure 22b) show them to be alumino-silicate in nature. Their smooth shape and minimum surface are configuration suggest that they have at some stage been molten in the boiler.
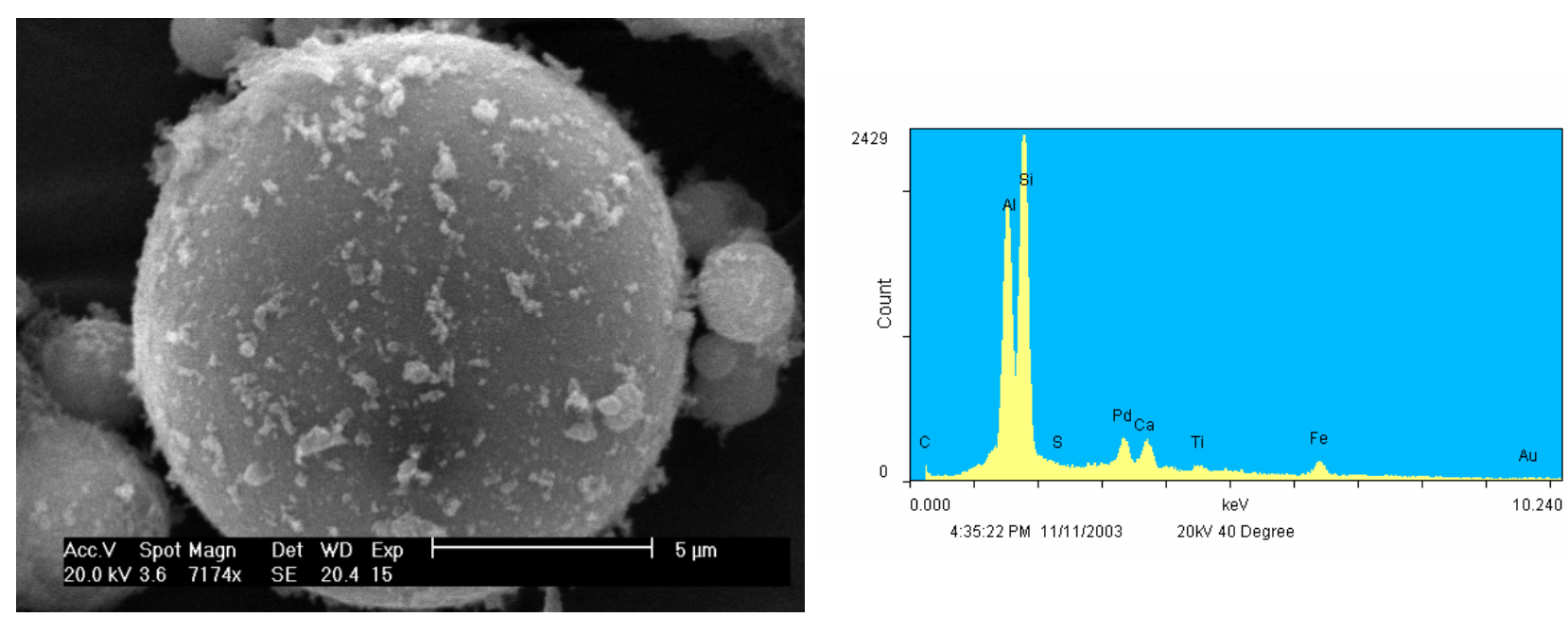

Figure 22: SEM Micrograph (a) and EDS Spectrum (b) From a Typical Spherical Morphology Alumino-Silicate Particle.

The third morphology frequently encountered in the Boiler A sample is shown in Figure 23. These are very large $(50-100 \mu \mathrm{m})$ hollow carbon particles with porous walls. Frequently, the shells are ruptured, allowing a view into their interior. They are usually hollow (Figure 23a), but sometimes are seen to enclose some of the smooth spherical alumino-silicate particles (Figure 23b). These structures always display smaller (1-2 $\mu \mathrm{m})$ spherical particles embedded within their walls as shown in Figure 24a. SEM-EDS mapping experiments, such as that shown in Figure 24b have given us some insight into the compositions of the smaller embedded particles. The color coding in Figure 24b is as follows; Green-Al, Light blue -Ca, Red - Fe, Dark Blue - Si, Pink - K and Yellow - Ti. It is clear that many of the particles are alumino-silicate in nature, and a much smaller fraction are $\mathrm{Fe}, \mathrm{Ti}$ and $\mathrm{Ca}$ containing particles. 

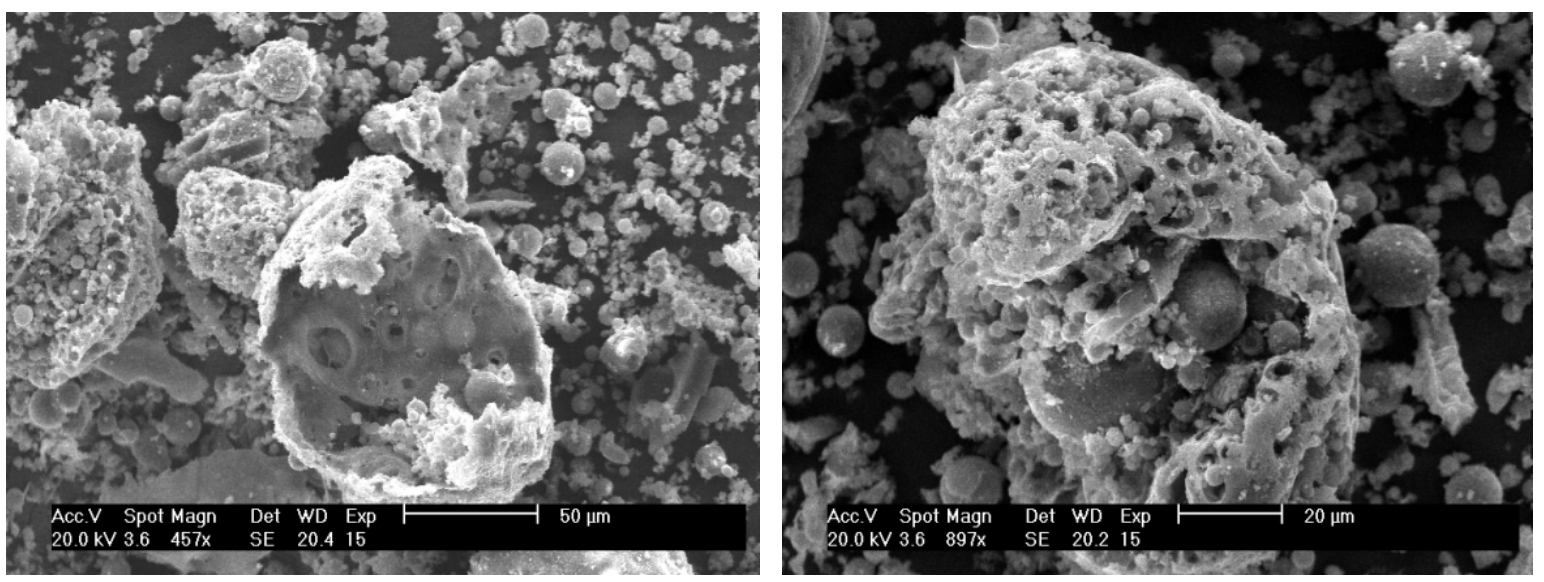

Figure 23: SEM Micrographs From Large Carbon Particles Having a Hollow Shell Morphology.
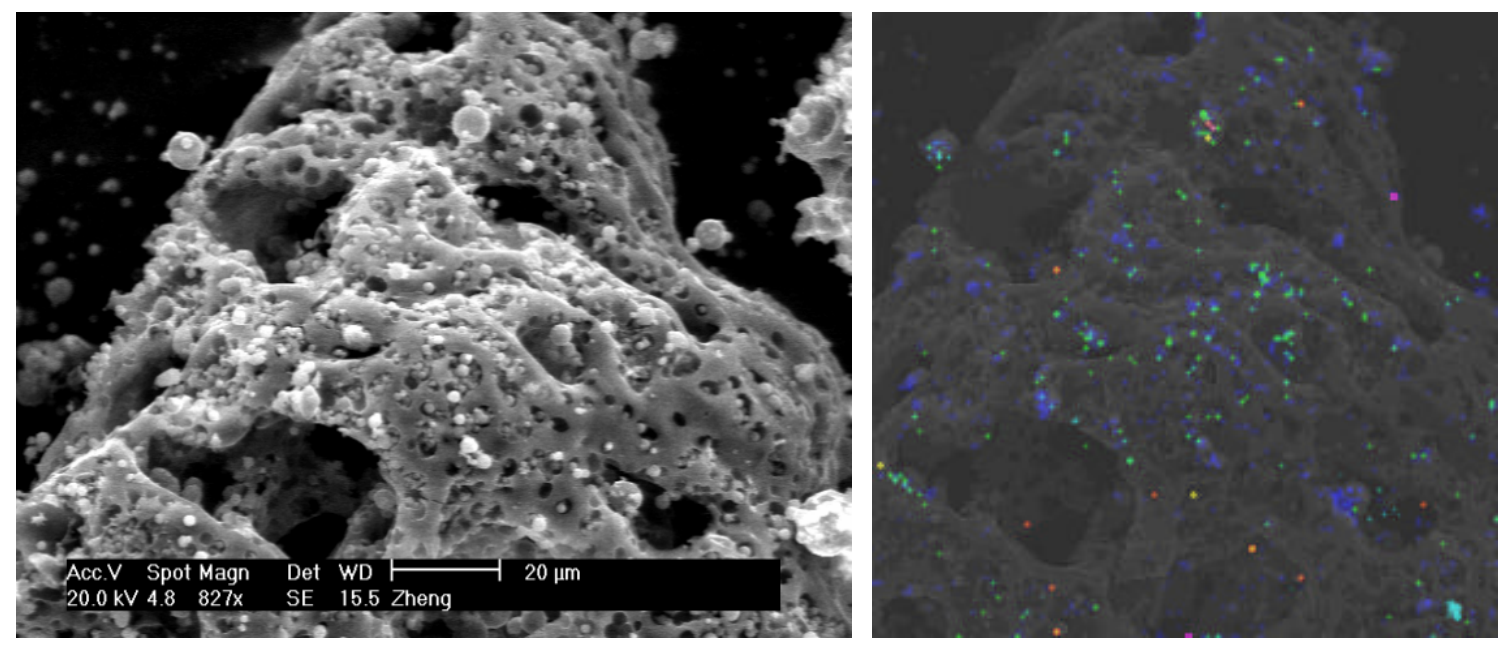

Figure 24: SEM Micrograph (a) and Corresponding EDS Elemental Map (b) From a Typical Hollow Morphology Carbon Particle.

A fourth, all pervasive, morphology present in the Boiler A sample is much finer irregularly shaped particles of carbon. TEM imaging experiments (Figure 25) showed these particles to be amorphous, typically $50-200 \mathrm{~nm}$ in size, and to have a tendency to agglomerate into larger clusters. Figure 26 demonstrates that these same carbon particles also have a strong tendency to cling to the alumino-silicate spheres and decorate their surfaces. Both EDS and XPS chemical analyses on this material failed to detect any trace of $\mathrm{Hg}$, suggesting that if present as an adsorbate on the fly ash surface, its concentration is well below the detectability level of either of these two analytical techniques. 


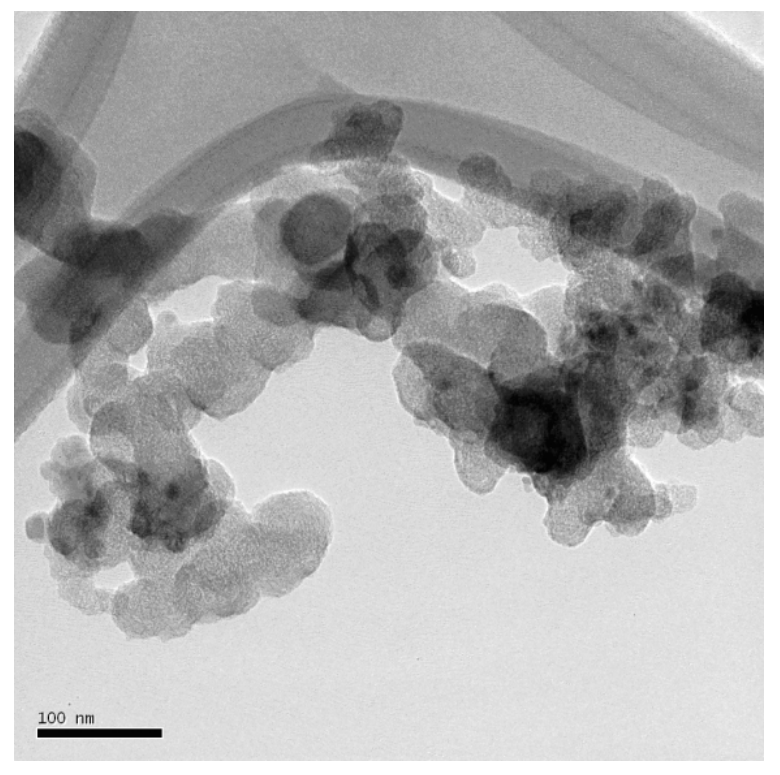

Figure 25: TEM Micrograph of a Typical Agglomerate of Activated Carbon Particles.

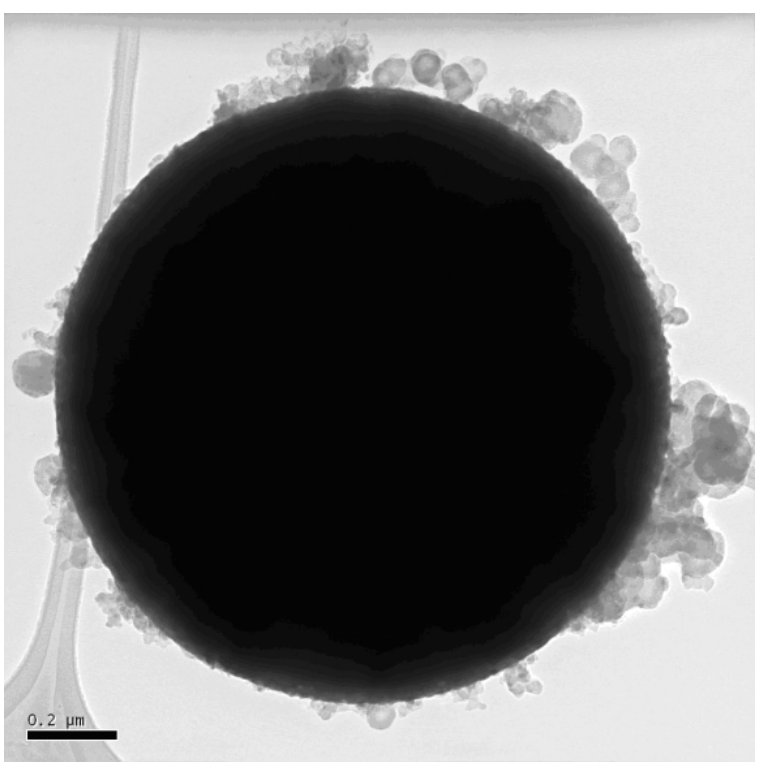

Figure 26: TEM Micrograph of an Alumino-Silicate Sphere Decorated with Activated Carbon Particles.

A sample of 'pure' activated carbon was also subjected to detailed SEM and TEM examination. Figure 27 shows an SEM micrograph of 'pure' AC. It is clear that the morphology is very different to that of the fly ash sample. Large $(20-50 \mu \mathrm{m})$ angular particles are apparent which are decorated with a population of smaller (brighter) particles. Figure 28 shows an EDS spectrum taken from the entire field of view shown in Figure 27. The 'pure' AC clearly contains impurities as evidenced by the presence of $\mathrm{Al}, \mathrm{Si}, \mathrm{Fe}, \mathrm{S}, \mathrm{Mg}$ and $\mathrm{Ca}$. It should be noted that the very low intensity of the $\mathrm{C}_{\alpha}$ signal in this spectrum is an artifact, because the particular EDS detector used is insensitive to very low energy $\mathrm{X}$-rays. EDS point spectra were also acquired from much more localized positions on the specimen, which indicated that the larger irregular particles are the carbon, whereas some (but not all) of the smaller brighter particles are the contaminant mineral phases. TEM imaging experiments were also carried out on these 'pure' AC samples as shown in Figures 29 and 30 which largely confirmed these findings. 


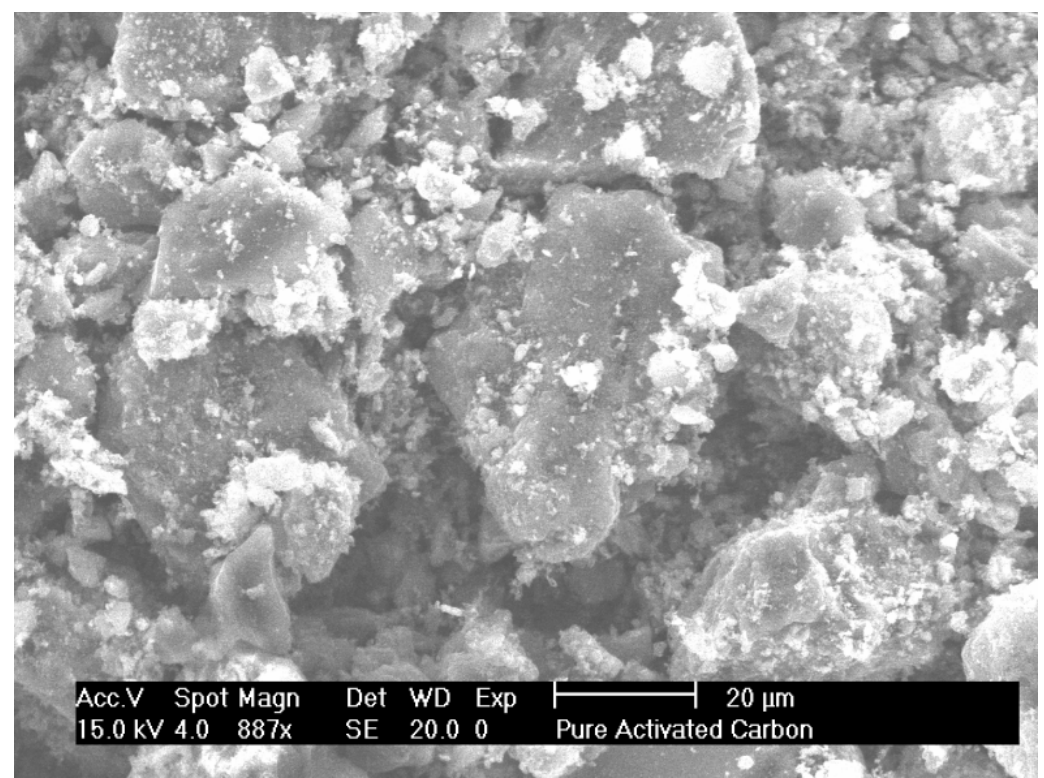

Figure 27: An SEM Micrograph Showing the Typical Morphology of a 'Pure' Activated Carbon Sample.

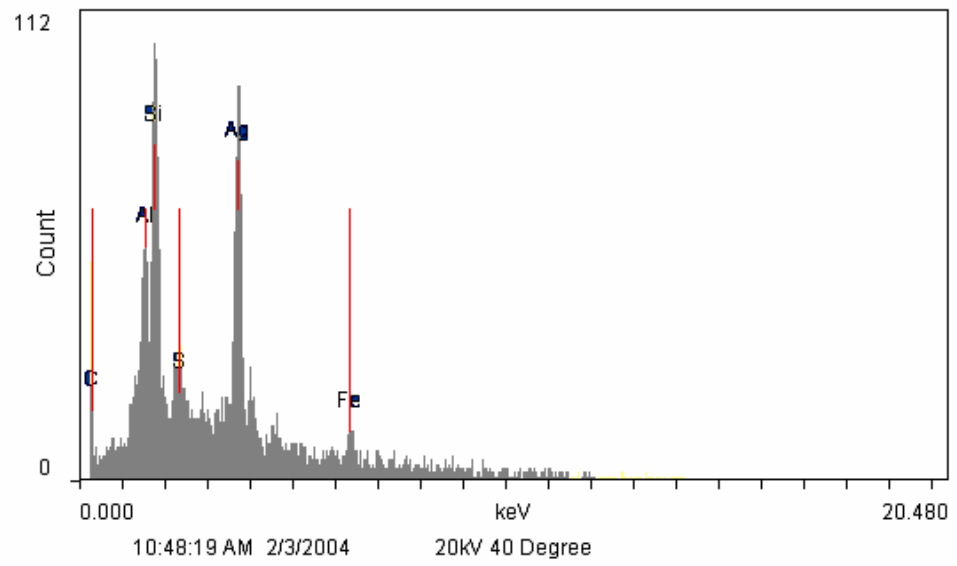

Figure 28: EDS Spectrum Obtained From the Entire Area Imaged in Figure 27. 


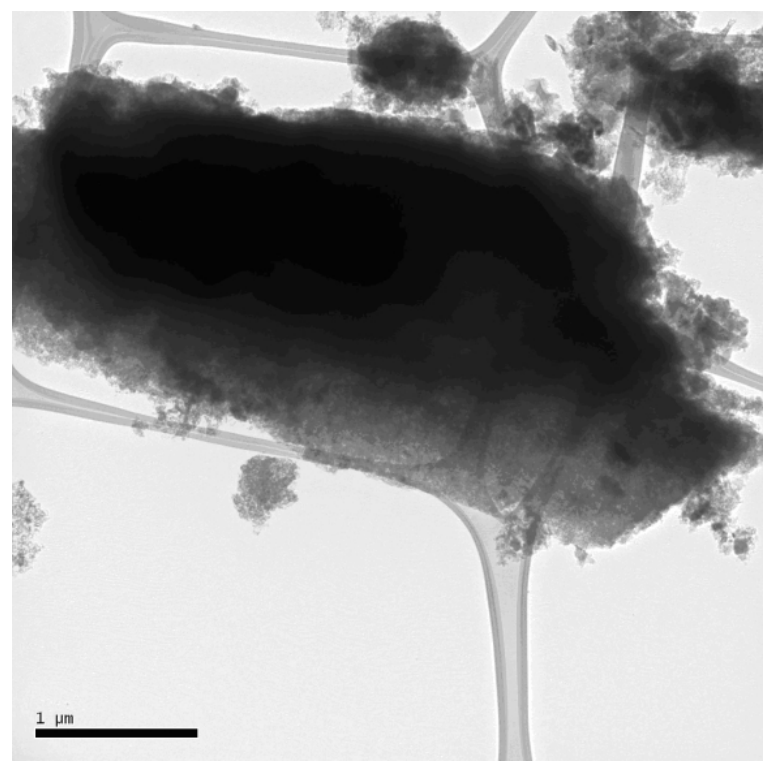

Figure 29: Bright Field TEM Micrograph Showing an Irregular Carbon Particle in the Pure AC Sample Decorated with Smaller Carbon Particles.

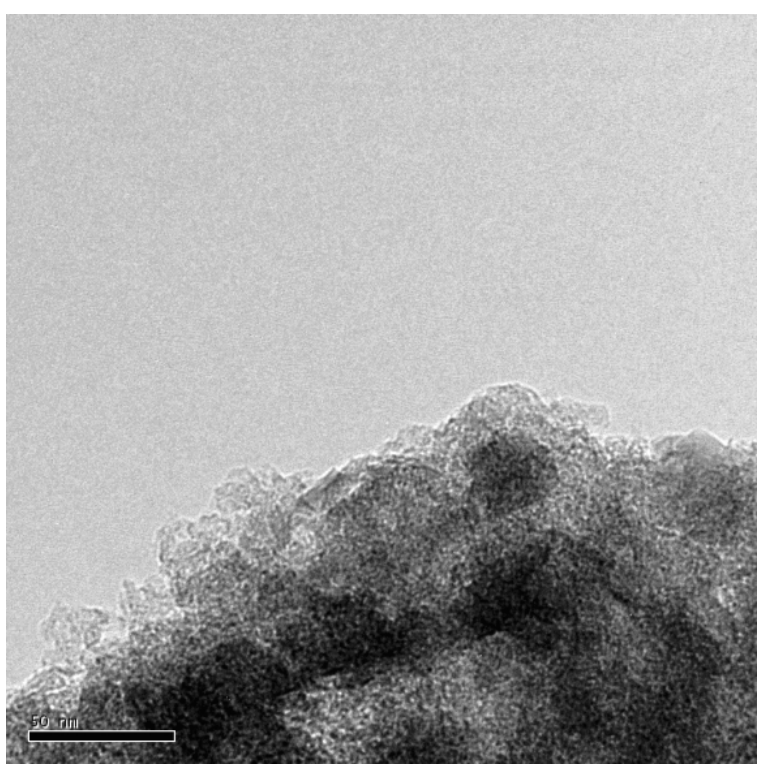

Figure 30: Higher Resolution Electron Micrograph of the Smaller Decoration Particles in Figure 29, Showing Them to be Amorphous Carbon.

\section{Additional Studies of Activated Carbon and Unburned Carbon in Fly Ash}

A second group of microscopy studies was performed during which the focus was on use of the Light Optical and Scanning Electron Microscopes to examine large activated carbon particles and char particles from fly ash.

Black and white optical microscopy images were taken with the camera attached to a Nikon Metaphot photo micrographic microscope. Objective lenses of 5X,10X, 20X and 50X were used in order to obtain the desired magnification levels when imaging fly ash and activated carbon particles. The Philips XL 30 Scanning Electron Microscopy was also utilized to image samples of fly ash and activated carbon. Most SEM measurements were performed with an electron accelerating voltage of $20.0 \mathrm{kV}$; others were set at $15.0 \mathrm{kV}$. The working distances were around $20 \mathrm{~mm}$, depending on the quality of the image. 
Four ash and activated carbon samples were e valuated. Two were obtained from the AC/fly ash mixture after it had been segregated in the fluidized bed. The sample from the top layer of the bed had 27 percent carbon and the sample from the bottom layer had 17 percent carbon (see Table 1). The other two samples were pure activated carbon (70 percent carbon) and a high carbon-content fly ash obtained from the electrostatic precipitator of a coalfired boiler. All of the carbon in the latter case was due to naturally occurring unburned carbon.

Table 1

Fly Ash and Activated Carbon Samples Examined

\begin{tabular}{|c|c|l|}
\hline Sample & $\begin{array}{c}\text { Carbon } \\
\text { (wt\%) }\end{array}$ & \multicolumn{1}{|c|}{ Sample Description } \\
\hline FA-1 Top Layer & 27 & Top layer after segregation from FA-1 \\
\hline FA-1 Bottom Layer & 17.2 & Bottom layer after segregation from FA-1 \\
\hline Pure Activated Carbon & 70 & Activated carbon before injection into boiler \\
\hline High Carbon Fly Ash & 68 & $\begin{array}{l}\text { High carbon fly ash without activated } \\
\text { carbon }\end{array}$ \\
\hline
\end{tabular}

Fly Ash/AC Mixture Obtained by Segregation. Figure 31 shows a relatively low magnification SEM image of the top layer fly ash with 27 percent carbon. Compared with Figure 32, which is the bottom layer fly ash with 17 percent carbon, the top layer had more irregularly shaped particles (which are larger and lighter) than the bottom layer. At the same time the bottom layer had more spherical mineral content particles than top layer. This is consistent with the segregation behavior in a bubbling fluidized bed where heavier and smaller particles tend to move to the bottom of the bed during the fluidization process while lighter and larger particles are likely to move toward the top of the bed. The white color on part of the spherical particles is due to charging effects in the SEM.

Pure Activated Carbon. Pure activated carbon particles were studied both by SEM and optical microscopy. Here the word "pure" is used compared with samples which contain both fly ash unburned carbon and activated carbon. The carbon content of this pure activated carbon is 70 percent. The particles in Figure 33, which were 


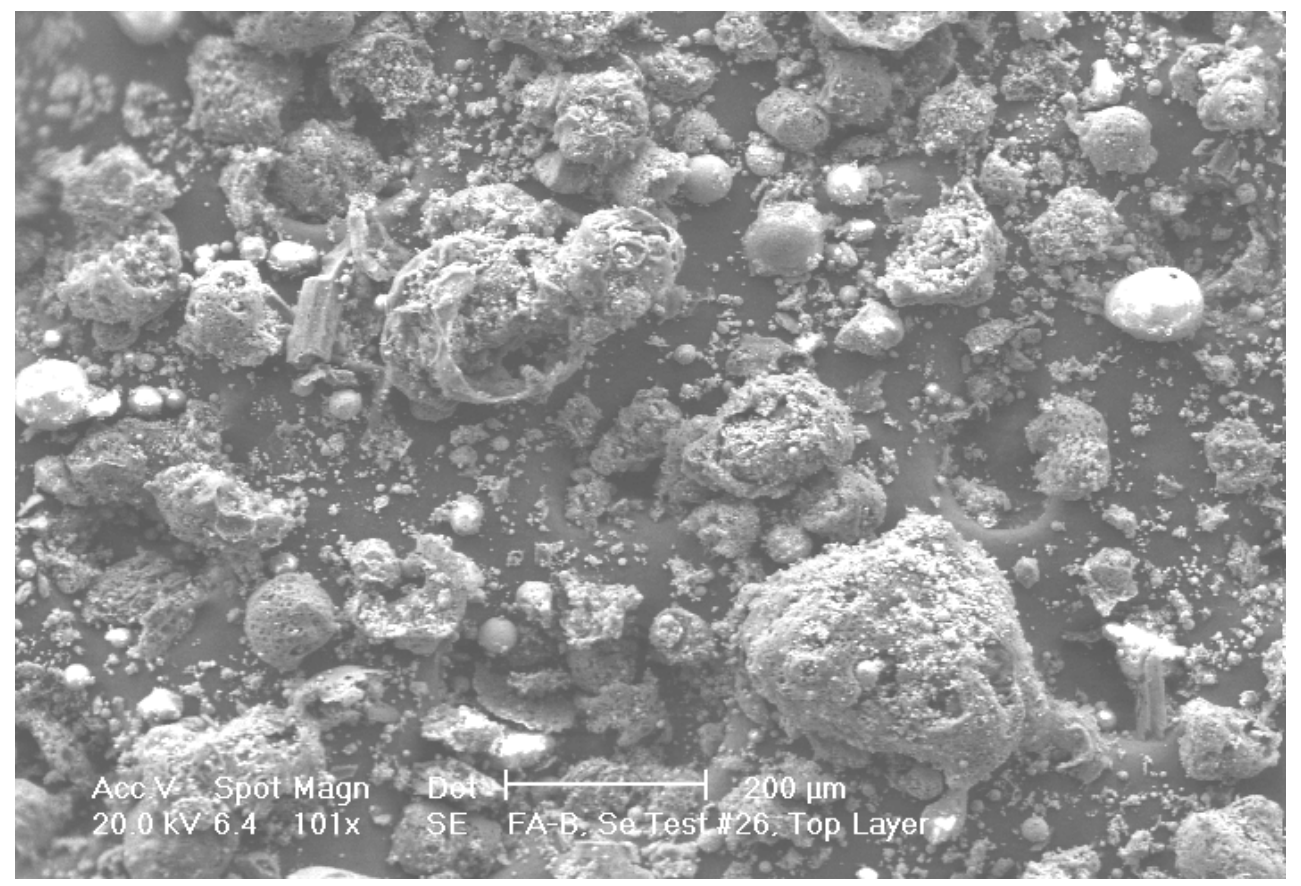

Figure 31: Top Layer of FA-1 Fly Ash Segregation.

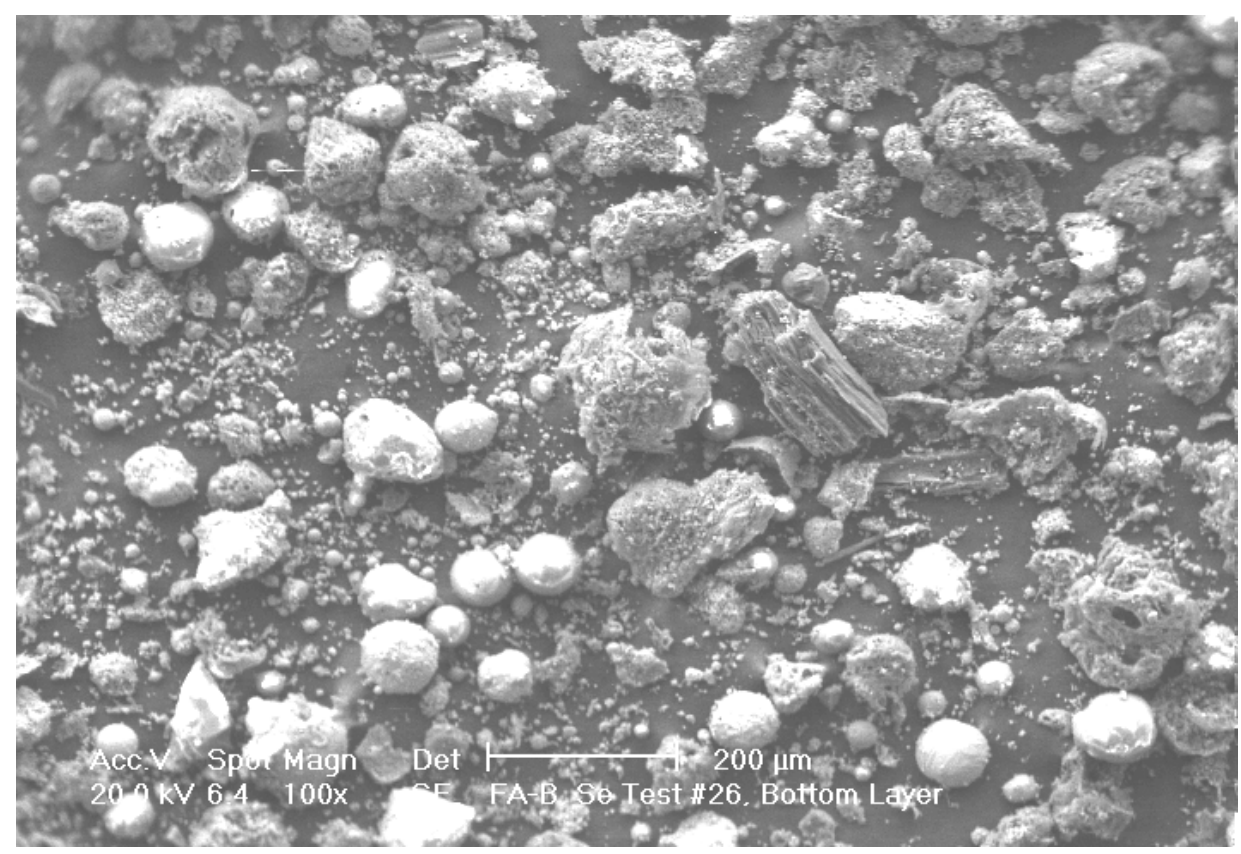

Figure 32: Bottom Layer of FA-1 Fly Ash Segregation. 


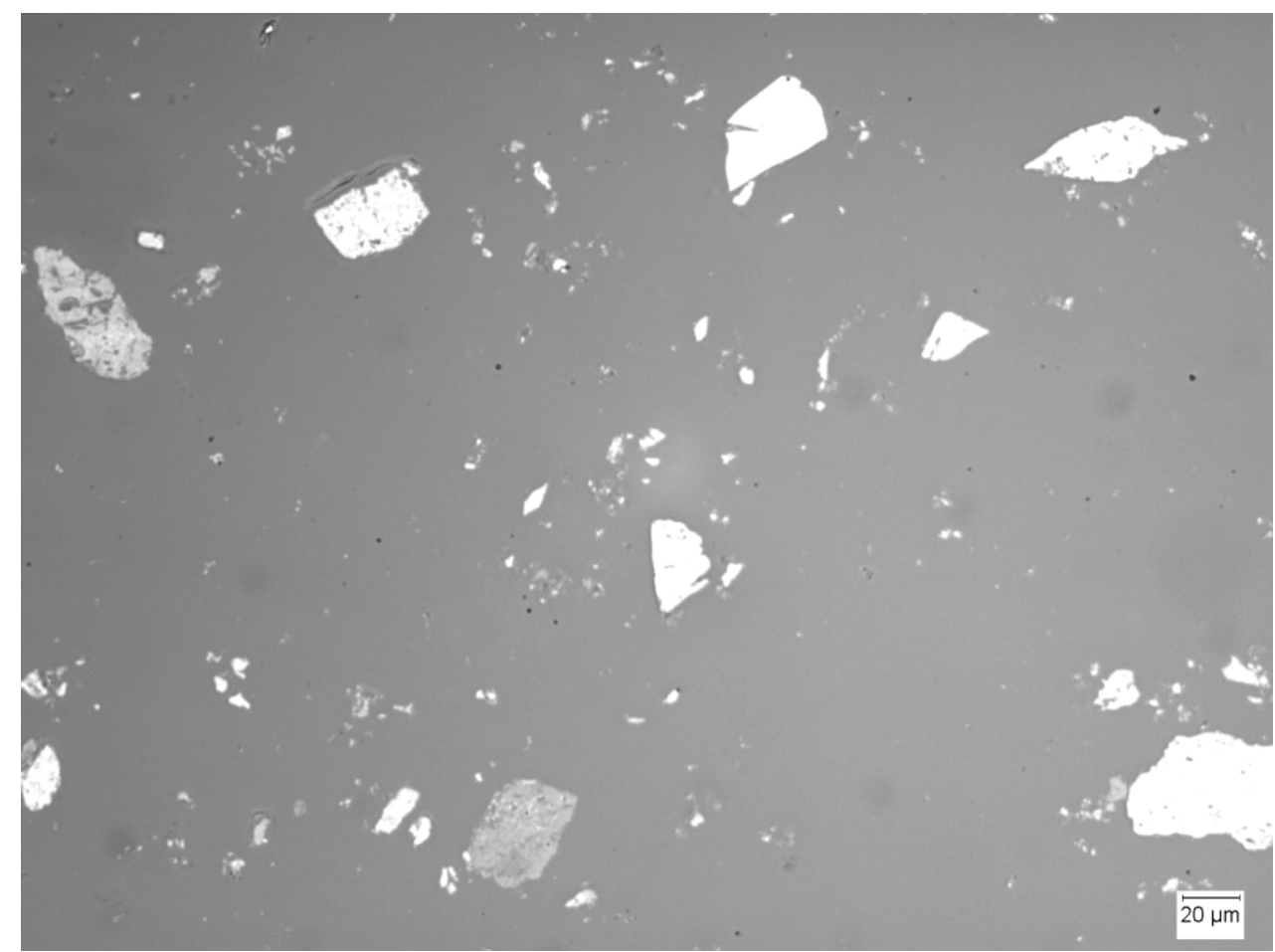

Figure 33: Optical Microscopy Image of Pure Activated Carbon Particles.

imaged by optical microscopy, appear to be mostly carbon particles with an average size about $30 \mu \mathrm{m}$. Most of the particles have sharp edges which is an indication of having not going through a softening stage. Figure 34 is a high magnification of a relatively large shale-shaped activated carbon particle.

Fly Ash With High Unburned Carbon. High carbon content fly ash from a utility boiler was used to study naturally occurring unburned carbon. The carbon content is 68 percent in Figure 35. Most of the visible particles are in the size range of $100 \mu \mathrm{m}$ and are of porous irregular shape and structure. From Figure 36, it can be seen that small spherical particles are attached to the surface and part of the particle looks like char. Optical microscopy images in Figures 37 and 38 also show that most particles in the vicinity are porous particles similar to the $A C$ particles depicted in Figures 33 and 34 . 


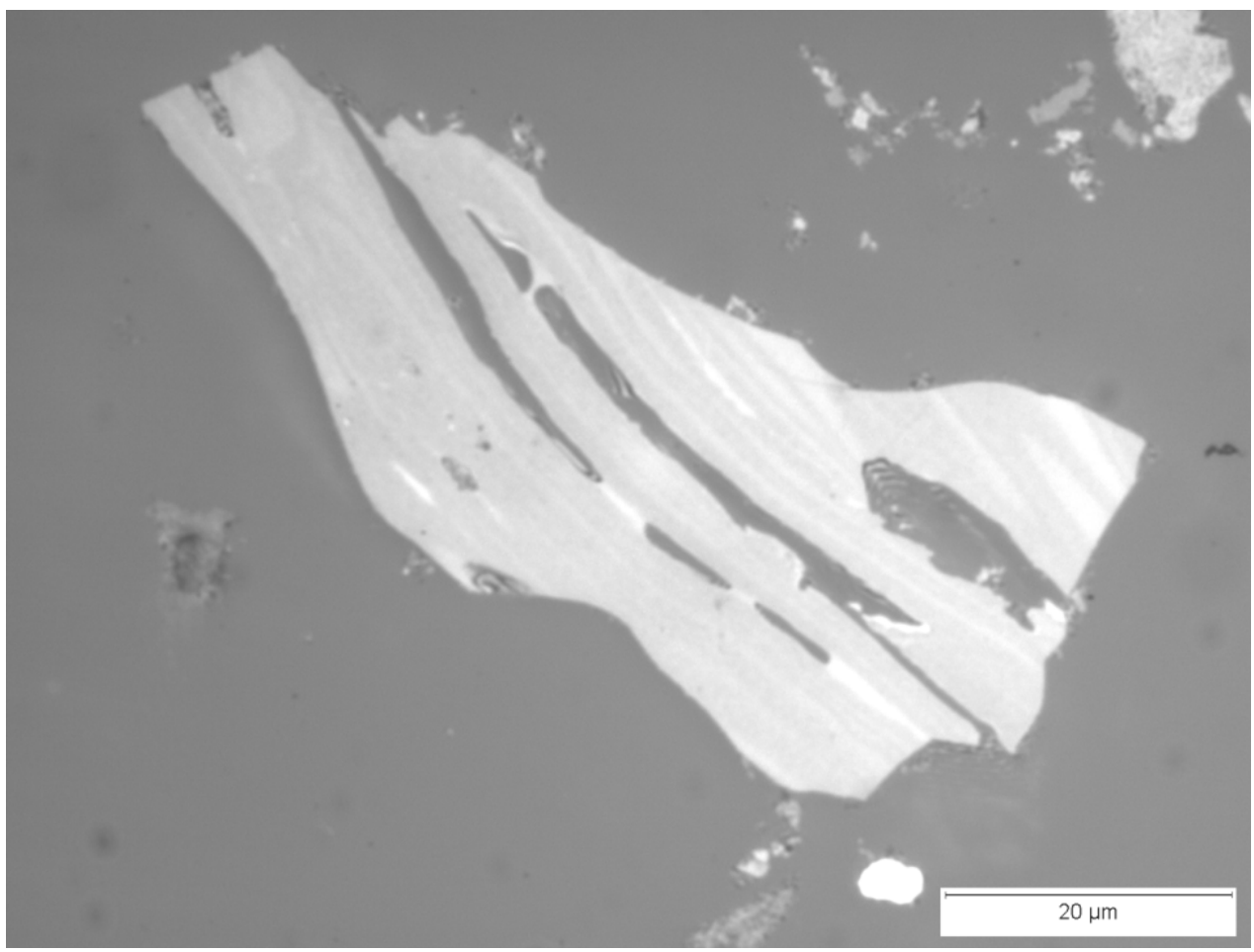

Figure 34: Optical Microscopy Image of Typical Pure Activated Carbon Particle.

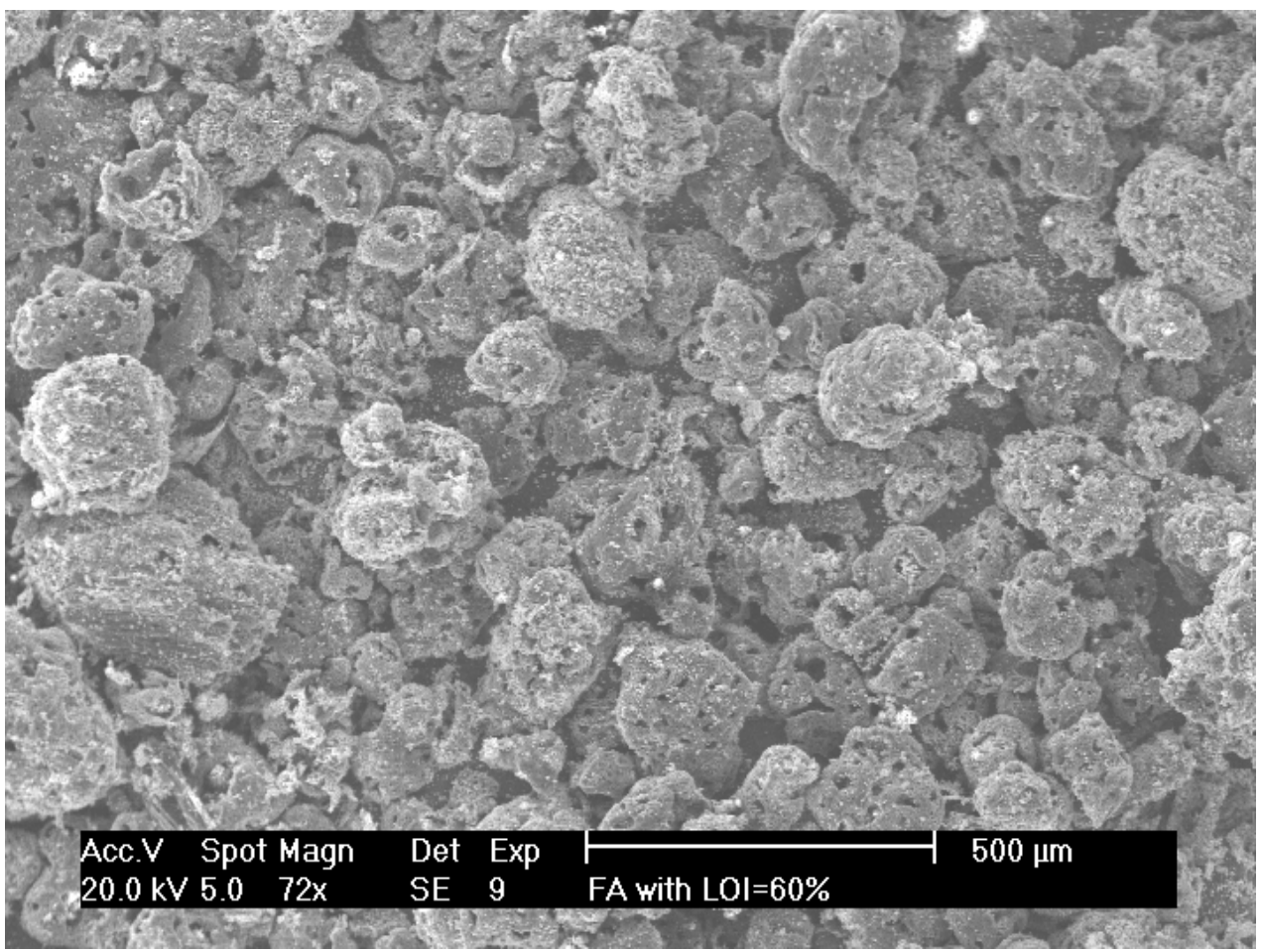

Figure 35: SEM Image of Fly Ash With High Unburned Carbon. 


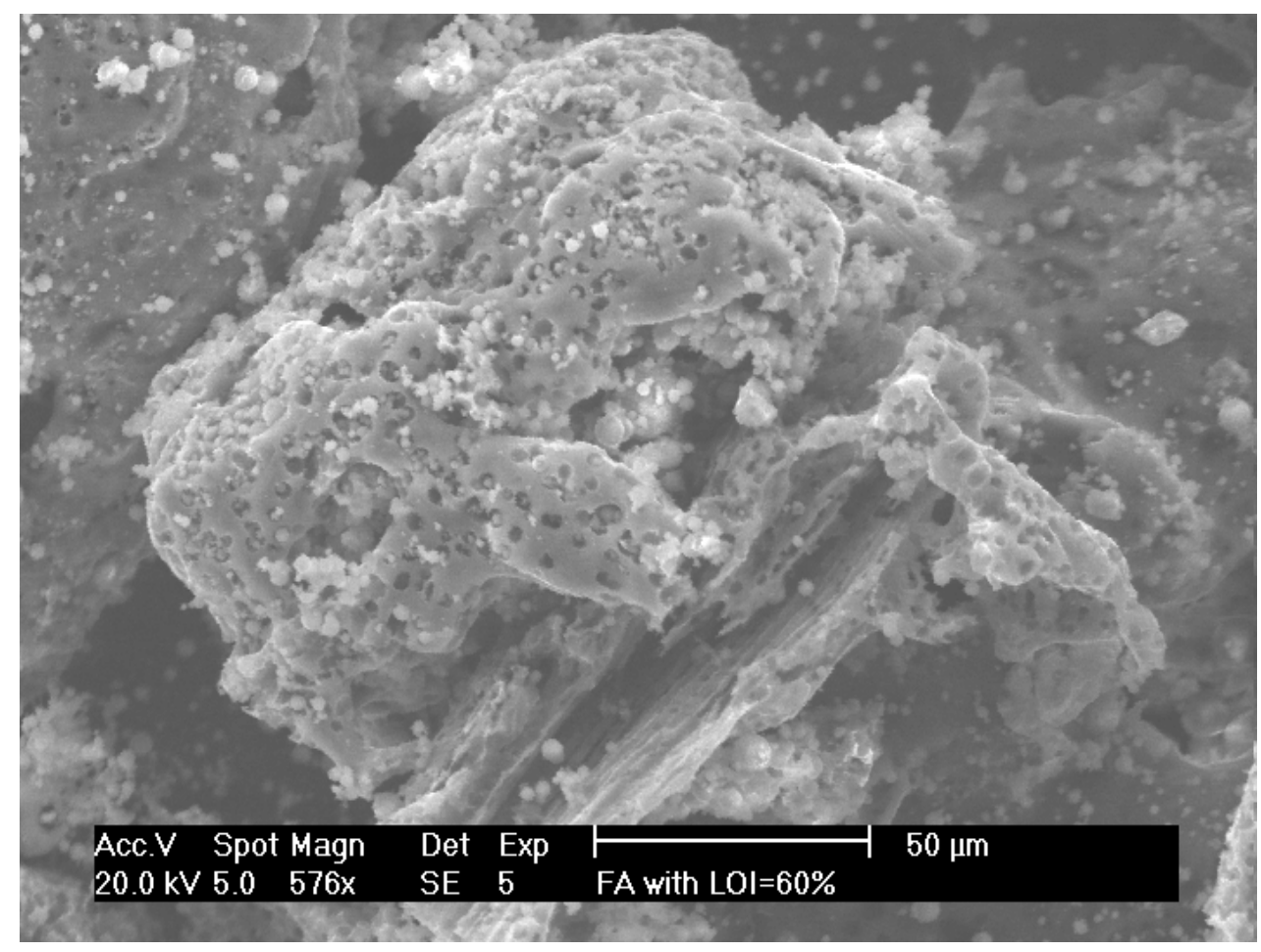

Figure 36: SEM Image of Typical Large Unburned Carbon Particle.

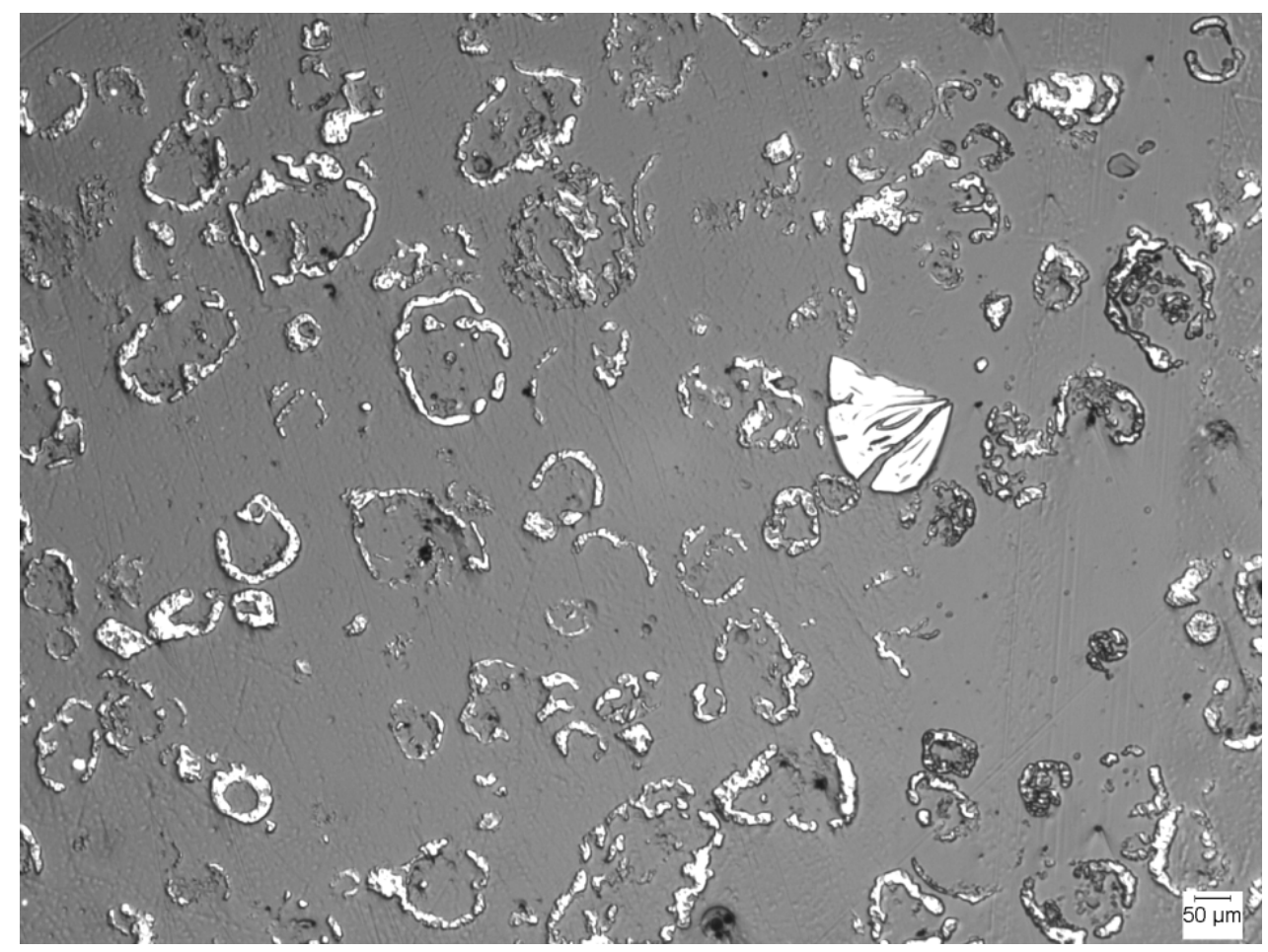

Figure 37: Optical Microscopy Image of Large Unburned Carbon Particles. 


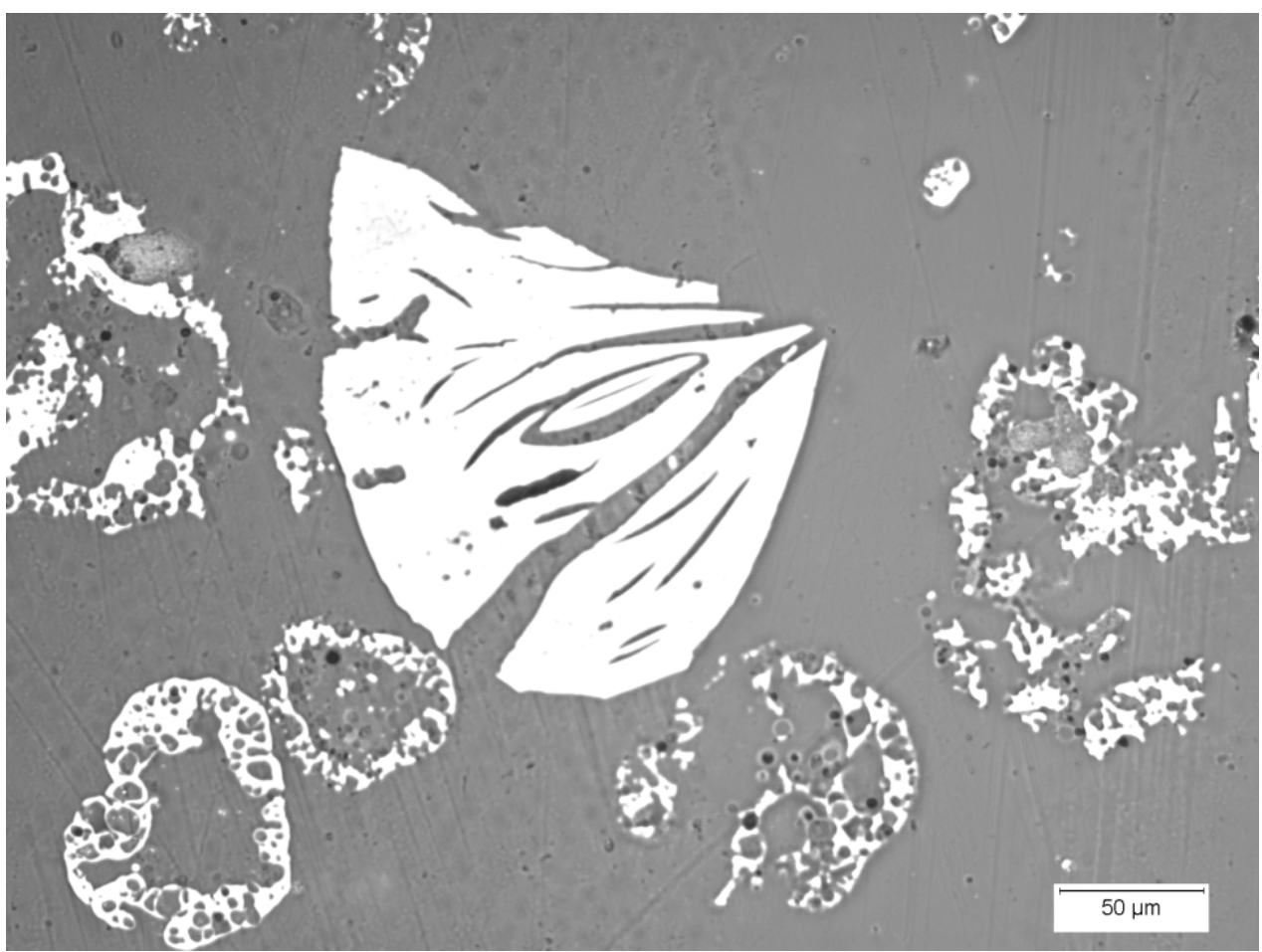

Figure 38: Optical Microscopy of Typical Large Unburned Carbon Particles.

\section{Detection of $\mathrm{Hg}$ on Individual Carbon Particles}

The microstructural characterization studies described above were used to examine the morphologies of activated carbon and various types of fly ash particles. Characterization studies were also performed in an effort to detect $\mathrm{Hg}$ on individual activated carbon particles. Two specimens, which were loaded to an artificially high level with $\mathrm{Hg}$, were studied. These had bulk $\mathrm{Hg}$ levels, as determined by atomic absorption spectroscopy, of 293ppm and $\sim 1000 \mathrm{ppm}$. Neither high resolution electron microscopy (HREM) nor annular dark field (ADF) scanning transmission electron microscopy showed any visual evidence (by phase or mass contrast) of $\mathrm{Hg}$ agglomeration. Energy dispersive $\mathrm{x}$-ray spectroscopy (XEDS) was also attempted on both samples, but was not sensitive enough to pick up any X-ray emission characteristic of $\mathrm{Hg}$. In hindsight, this is not so surprising as the XEDS technique is essentially a high spatial resolution bulk method with a detectibility limit of about $0.2 w t \%$. Our combined TEM-based imaging and XEDS measurements suggested that the $\mathrm{Hg}$ atoms were not obviously clustering to give $\mathrm{Hg}$-containing nanoparticles or droplets. This led us to conclude that if the $\mathrm{Hg}$ is not being immediately desorbed by interaction with the 
incident electron beam, it was most likely present in a highly dispersed form (maybe even atomically dispersed) on the activated carbon sorbent.

The same two samples were also analyzed using the X-ray photoelectron spectroscopy (XPS) technique on the Lehigh Scienta-300 instrument. The XPS signals are only collected from the first few atomic layers of the sample, and thus should intrinsically be more sensitive to the surface chemistry and surface adsorbates. Unfortunately none of the XPS spectra collected showed any clear evidence that confirmed the presence of $\mathrm{Hg}$. Even though the XPS experiments were carried out at low (i.e. liquid $\mathrm{N}_{2}$ ) temperatures, there was still no detectable $\mathrm{Hg}$ signal. This means either (i) the $\mathrm{Hg}$ is evaporating during the instrument pump-down to UHV, (ii) the $\mathrm{Hg}$ is not surface segregating enough to approach the instrumental detection limit, or (iii) the $\mathrm{Hg}$ is trapped sub-surface in some internal pore structure. A quick experiment to eliminate the third possibility was carried out by heating the sample in-situ within the Scienta instrument to around $300^{\circ} \mathrm{C}$ in an attempt to force any sub-surface $\mathrm{Hg}$ to migrate out of any internal pores onto the surface and possibly become detectable. No $\mathrm{Hg}$ signal was detectable after heating.

In summary, our attempts to detect $\mathrm{Hg}$ in these artificially heavily loaded activated carbon samples by TEM and XPS all turned out to be unsuccessful. The AES and AAS techniques are still the only techniques available at Lehigh with sufficient sensitivity to pick up adsorbed $\mathrm{Hg}$ on the ppm. level. However, these two methods lack spatial resolution and are incapable of discriminating between cationic and elemental $\mathrm{Hg}$. Interestingly, there has been a recent report that the bulk EXAFS/XANES technique (Ref. 10) can in some favorable instances pick up cationic $\mathrm{Hg}^{2+}$ on carbonaceous sorbents with concentrations in excess of $300 \mathrm{ppm}$. Such specialized experiments, however, need to be carried out on a synchrotron source.

\section{Microstructural Characterization of Fly Ash Passing Through SCR Catalysts}

Fly ash was obtained by sampling isokinetically across the gas ducts, both upstream and downstream, of SCR reactors. The two materials were subjected to 
comparative TEM and XPS studies to see if there is any significant difference in their surface chemistry.

The morphology of the 'before' and 'after' SCR fly ash samples were essentially identical as observed by TEM observation. Figures 39 to 41 show representative images of the various morphologies observed in both samples. Figure 39 is a low magnification micrograph showing an intimate mixture of large agglomerates of tiny carbon particles and spherical fly ash particles. Figure 40 shows a spherical fly-ash particle about $0.7 \mu \mathrm{m}$ in diameter whose surface is decorated with much finer carbon particles. Figure 41 shows a higher magnification image of an aggregate of carbon particles showing that the primary particle size is the $20-50 \mathrm{~nm}$ range. Electron diffraction images from such regions showed these carbon nanoparticles to be amorphous in nature.

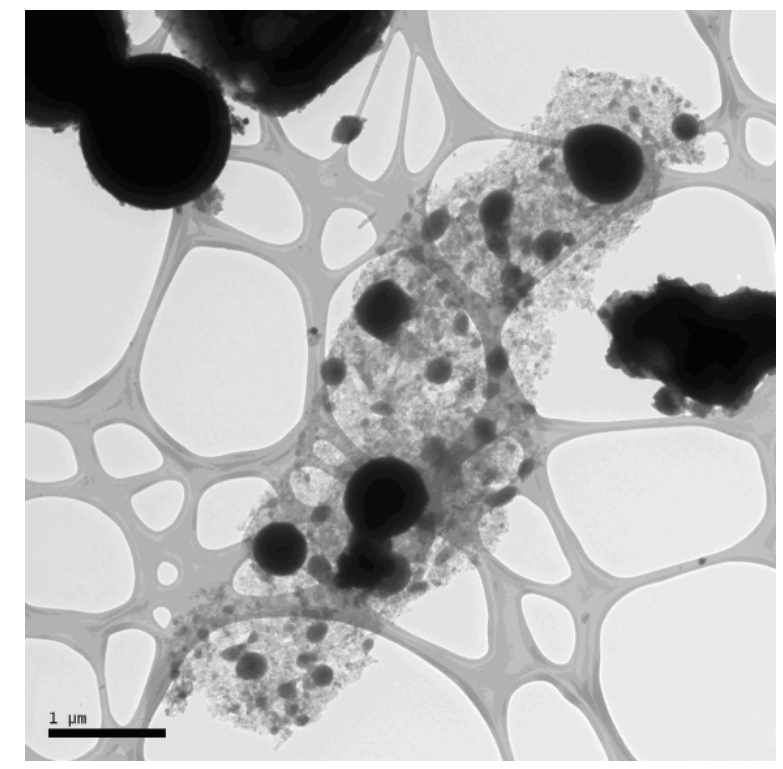

Figure 39: Bright Field Low Magnification Micrograph of the 'After' SCR Samples. 


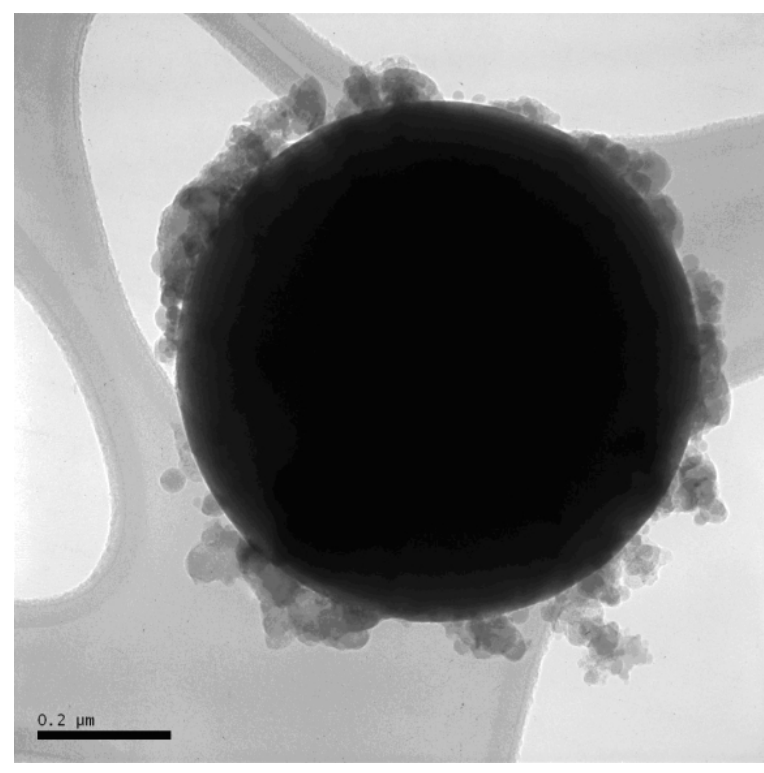

Figure 40: Bright Field Micrograph of a Typical Spherical Fly Ash Sample Showing Surface Decoration with Carbon.

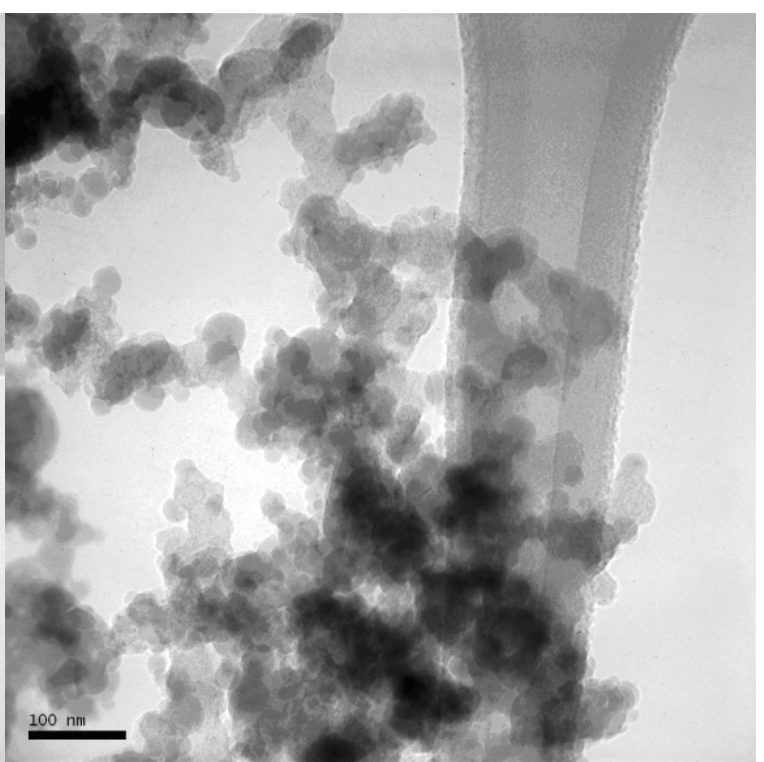

Figure 41: High Resolution Bright Field Micrograph of an Agglomerate of Amorphous Carbon Particles.

Chemical analyses of the 'before' and 'after' SCR samples were attempted by both TEM-EDS and XPS. The EDS analysis was inconclusive, showing the existence of $\mathrm{C}, \mathrm{Si}, \mathrm{Al}, \mathrm{O}, \mathrm{Fe}$ and $\mathrm{Ca}$ in both samples. The XPS analysis, which is much more surface sensitive, was more interesting. Figure 42 shows the widescan survey spectra from both samples, indicating the additional presence of $\mathrm{Cl}$ and $\mathrm{S}$ along with some another minor peaks. Higher resolution spectra over a more limited ( $0-500 \mathrm{ev})$ binding energy range are shown in Figure 43, in which characteristic transitions from $\mathrm{Na}$, Ti \& N can also been seen. The most significant differences between the surface chemistries of the two fly-ash samples are as follows:

- The 'after' SCR material has a significant surface $\mathrm{Cl}$ content, while the 'before' SCR material is essentially devoid of $\mathrm{Cl}$.

- The surface S signal in the 'after' SCR sample is about half of that observed in the 'before' SCR sample.

- The surface Fe content shows the opposite trend to the $\mathrm{S}$ signal. It increases by about $50 \%$ in the 'after' SCR sample. 


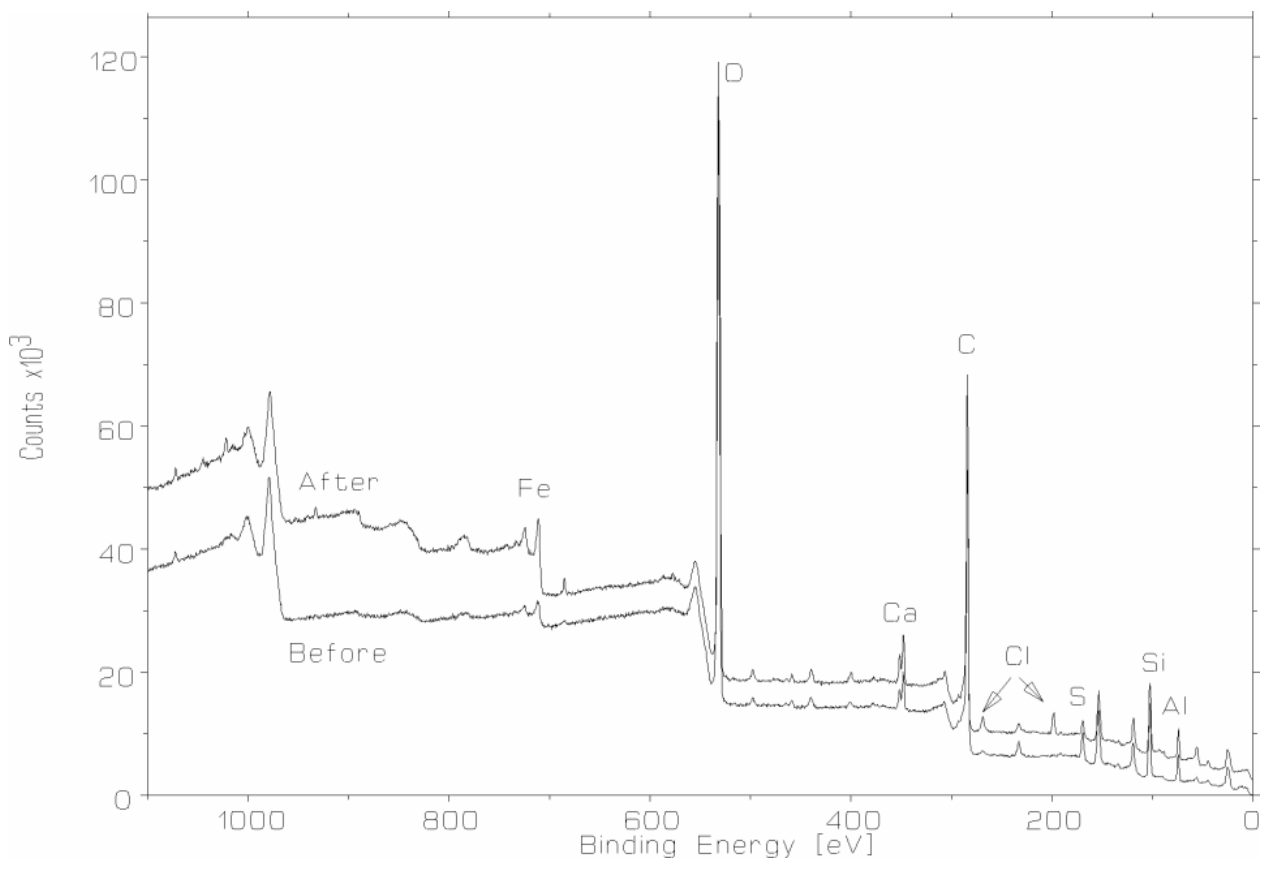

Figure 42: Widescan XPS Survey Spectra of the 'Before' and 'After' SCR Materials.

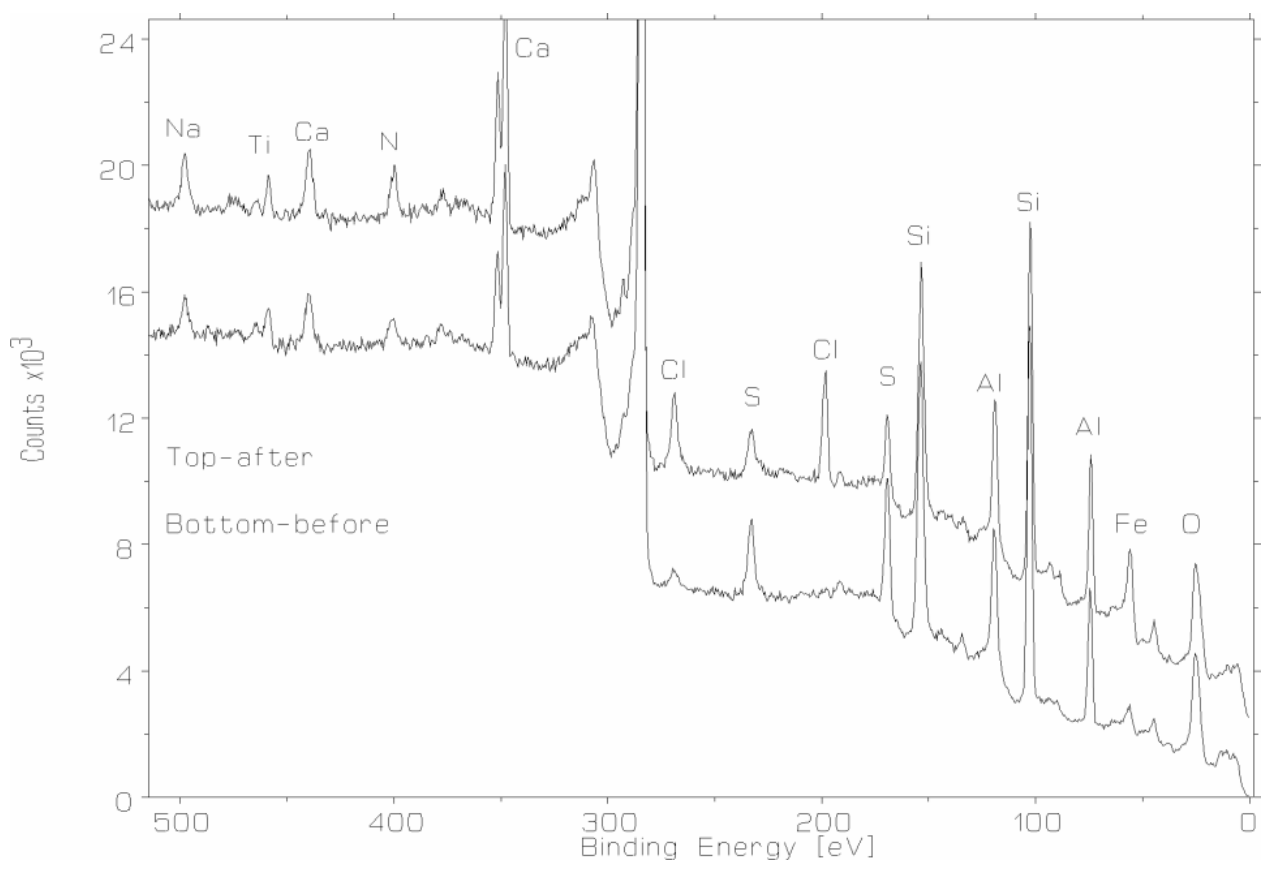

Figure 43: Higher Resolution XPS Spectra From the 'Before' and 'After' SCR Materials.

The other surface concentrations of the other elements were essentially the same in both the 'before' and 'after' SCR specimens. 


\section{SUMMARY AND CONCLUSIONS}

Separation of Activated Carbon and Fly Ash in a Fluidized Bed. Experiments were performed with a mixture of activated carbon and fly ash to determine to what extent the unburned carbon in the fly ash and the activated carbon can be separated from the inert portion of the fly ash in a bubbling fluidized bed. The data show that carbon segregation is very sensitive to superficial gas velocity, with the strongest segregation occurring at superficial velocities of 0.7 to $0.8 \mathrm{~cm} / \mathrm{s}$. At these conditions, the carbon content at the top of the bed was approximately 27 percent and it was less than 17 percent in the bottom layer. Very little or no carbon segregation occurred at fluidization velocities much lower than 0.7 to $0.8 \mathrm{~cm} / \mathrm{s}$ or higher than $1.1 \mathrm{~cm} / \mathrm{s}$.

While these experiments show it is possible to achieve carbon separation in a bubbling fluidized bed, the differences in particle density between the carbon particles and the inert fly ash particles appear not to be large enough to make this separation approach practical for commercial applications. There are other particle separation techniques based on triboelectric and electrostatic principles, and these might be better suited for this application. It is recommended that feasibility tests be performed on $\mathrm{AC} /$ fly ash mixtures using the triboelectric and electrostatic approaches.

\section{Relation Between Mercury Concentration and Carbon Content. Multistage} separation experiments were performed on the AC/fly ash mixture to expand the range of carbon contents between the top and bottom layers of the fluidized bed. Analyses of carbon and bulk mercury contents of the samples obtained from these tests show a strong linear relationship between $\mathrm{Hg}$ and carbon content, with the bulk $\mathrm{Hg}$ content approaching zero as the carbon content of the material goes towards zero.

Removal of $\mathrm{Hg}$ from Activated Carbon and Fly Ash. Elevated temperature fluidized bed experiments were performed on the low carbon content mixture from the bottom layers of the fluidized bed, on the high carbon content mixture from the top layers of the fluidized bed and on AC/ash mixture with average carbon content. All behaved qualitatively the same way, with a constant $\mathrm{Hg}$ content until a critical temperature was 
reached and then with rapidly decreasing $\mathrm{Hg}$ content as the temperature was increased to higher levels. The critical temperature was found to be a linear function of carbon content, increasing from $330^{\circ} \mathrm{C}$ at 17 percent carbon to $370^{\circ} \mathrm{C}$ at 33 percent carbon. The temperature at which all of the $\mathrm{Hg}$ was removed is in the 450 to $500^{\circ} \mathrm{C}$ range.

These results confirm that it is possible to remove $\mathrm{Hg}$ from $\mathrm{AC}$ and fly ash particles by heating the material in air, but that particle temperatures as high as $500^{\circ} \mathrm{C}$ would be needed to remove all the $\mathrm{Hg}$. If it were desired to use this approach to regenerate used $A C$, experiments would first be needed to determine if the $\mathrm{Hg}$ adsorption properties of the $A C$ are changed by having been heated to these temperatures.

The test results also show that the $\mathrm{Hg}$ on fly ash and $\mathrm{AC}$ will not be released to the atmosphere through heating of the material, provided the temperatures do not exceed $300^{\circ} \mathrm{C}$.

Morphologies of Fly Ash and Activated Carbon. Scanning Electron (SEM) and Transmission Electron (TEM) Microscopes were used to study the physical and chemical characteristics of the $\mathrm{AC}$ / ash mixture used in the fluidized bed separation experiments. Five distinct morphologies were identified: large (30-100 $\mu \mathrm{m})$ irregularlyshaped carbon particles, 0.1 to $20 \mu \mathrm{m}$ spherical alumino-silicate particles, 50-100 $\mu \mathrm{m}$ hollow carbon particles with porous walls, fine 50-200 nm amorphous carbon particles, and large 20-50 $\mu \mathrm{m}$ angular activated carbon particles.

Four additional ash and activated carbon samples were then evaluated by Light Optical and Scanning Electron Microscopy. SEM studies of the fly ash/AC mixture obtained from the fluidized bed segregation experiments showed marked differences between the materials from the top and bottom layers of the fluidized bed. The top layer was dominated by large, irregularly shaped particles while the bottom layer had more spherical high-mineral content particles. This finding is consistent with the physical mechanism of segregation which results in denser, smaller particles moving downward towards the distributor and lighter, larger particles floating at the top of the bed. 
Light Optical Microscopy images of large (50 to 100 microns) activated carbon particles showed them to be irregular in shape and filled with voids. Light Optical Microscopy studies of a fly ash, with a high naturally-occurring carbon content, showed the carbon in fly ash (usually referred to as unburned carbon) has an internal structure which is similar in appearance to that of pure activated carbon.

Detection of $\mathrm{Hg}$ on Individual Carbon Particles. Measurements were performed with both Transmission Electron Microscopy (TEM) and X-Ray Photoelectron Spectroscopy (XPS) in an attempt to detect $\mathrm{Hg}$ on individual carbon particles. The results showed the $\mathrm{Hg}$ concentrations were too small to be detected by either measurement method.

Effect of SCR on Fly Ash Surface Chemistry. Samples of fly ash were obtained from a boiler with a Selective Catalytic Reduction (SCR) reactor for $\mathrm{NO}_{x}$ control. These samples, which were obtained from upstream and downstream of the SCR, were analyzed by X-ray Photoelectron Spectroscopy (XPS) to determine the effects of the SCR on the surface chemistry of the fly ash. The most significant differences were as follows:

- The 'after' SCR material had a significant surface $\mathrm{Cl}$ content, while the 'before' SCR material was essentially devoid of $\mathrm{Cl}$.

- The surface S signal in the 'after' SCR sample was about half of that observed in the 'before' SCR sample.

- The surface Fe content shows the opposite trend to the $S$ signal. It was about 50 percent larger in the 'after' SCR sample than in the 'before' SCR sample.

\section{REFERENCES}

1. Kozanoglu, B. and E. Levy, "Transient Mixing of Homogeneous Solids in a Bubbling Fluidized Bed," in AIChE Symposium Series Number 281, Vol. 87, 1991, p. 58. 
2. Kozanoglu, B. and E. K. Levy, "Mixing Dynamics in a Bubbling Fluidized Bed with Binary Solids," in Fluidization VII, ed. by O. Potter and D. Nicklin, published by Engineering Foundation, 1992.

3. Belba, V. et al., "The Effects of Carbon Properties on Electrostatic Precipitator Performance Modeling," Proceedings Power Plant Air Pollution Control "Mega" Symposium, Baltimore, Maryland, August 28-31, 2006.

4. D. Geldart, "Types of Gas Fluidization," Powder Technology, Vol. 7, No. 5, pp. 285292, 1993.

5. Levy, E., I. Shnitzer, T. Masaki, and J. Salmento, "Effects of An Acoustic Field on Bubbling in a Gas Fluidized Bed," Powder Technology, 90 (1997), pp. 53-57.

6. Herrera, C. and E. Levy, "Bubbling Characteristics of Sound-Assisted Fluidized Beds," Powder Technology, 119 (2001), pp. 229-240.

7. D. Hassett, et al., "Mercury Release From Coal Combustion By-Products to the Environment," in Proceedings of the 1999 International Ash Utilization Symposium, Lexington, Kentucky, October 8-20, 1999.

8. H. Biester, et al., "Solubility and Changes of Mercury Binding Forms in Contaminated Soils After Immobilization Treatment," Environ. Sci. Technology, 1998, 32, 2755-2762.

9. Rubel, A., J. Hower and M. Zimmerer, "Thermal Stability of Mercury Captured by Ash: Part 2," Proceedings of 2005 World of Coal Ash, Lexington, Kentucky, April 11-15, 2005.

10. Hughes, F. E., N. Yap, G. P. Huffman and C. L. Senior, "XAFS Characterization of Mercury Captured From Combustion Gases On Sorbents at Low Temperatures," Fuel Processing Technology, 82, (2003), 167-196. 